\begin{tabular}{|c|l|}
\hline Title & Synthesis and magnetic properties of 12L-perovskites BaAL nI r3012 (Ln = lanthanides) \\
\hline Author(s) & Shimoda, Y uki; Doi, Y oshihiro; Wakeshima, Makoto; Hinatsu, Y ukio \\
\hline Citation & $\begin{array}{l}\text { Journal of Solid State Chemistry, 182(10), 2873-2879 } \\
\text { https://doi.org/10.1016/.jssc.2009.07.056 }\end{array}$ \\
\hline Issue Date & 2009-10 \\
\hline Doc URL & http://hdl.handle.net/2115/39663 \\
\hline Type & article (author version) \\
\hline File Information & JSSC182-10_p2873-2879.pdf \\
\hline
\end{tabular}

Instructions for use 


\title{
Synthesis and Magnetic Properties of 12L-Perovskites
}

\author{
$\mathrm{Ba}_{4} \mathrm{LnIr}_{3} \mathrm{O}_{12}(\mathrm{Ln}=$ Lanthanides $)$
}

Yuki Shimoda, Yoshihiro Doi, Makoto Wakeshima and Yukio Hinatsu

Division of Chemistry, Hokkaido University, Sapporo 060-0810, Japan 


\begin{abstract}
New quadruple perovskite oxides $\mathrm{Ba}_{4} \mathrm{LnIr}_{3} \mathrm{O}_{12}(\mathrm{Ln}=$ lanthanides $)$ were prepared and their magnetic properties were investigated. They crystallize in the monoclinic 12L-perovskite-type structure with space group $\mathrm{C} 2 / \mathrm{m}$. The $\mathrm{Ir}_{3} \mathrm{O}_{12}$ trimers and $\mathrm{LnO}_{6}$ octahedra are alternately linked by corner-sharing and form the perovskite-type structure with 12 layers. The Ln and Ir ions are both in the tetravalent state for $\mathrm{Ln}=\mathrm{Ce}, \mathrm{Pr}$, and $\mathrm{Tb}$ compounds $\left(\mathrm{Ba}_{4} \mathrm{Ln}^{4+} \mathrm{Ir}^{4+}{ }_{3} \mathrm{O}_{12}\right)$, and for other compounds $(\mathrm{Ln}=\mathrm{La}, \mathrm{Nd}, \mathrm{Sm}-\mathrm{Gd}, \mathrm{Dy}-\mathrm{Lu}), \mathrm{Ln}$ ions are in the trivalent state and the mean oxidation state of Ir ions is $+4.33\left(\mathrm{Ba}_{4} \mathrm{Ln}^{3+} \operatorname{Ir}^{4.33+}{ }_{3} \mathrm{O}_{12}\right)$. An antiferromagnetic transition has been observed for $\mathrm{Ln}=\mathrm{Ce}, \mathrm{Pr}$, and $\mathrm{Tb}$ compounds at $10.5,35$, and $16 \mathrm{~K}$, respectively, while the other compounds are paramagnetic down to $1.8 \mathrm{~K}$.
\end{abstract}




\section{Introduction}

The perovskite oxides $\mathrm{ABO}_{3}$ form a wide family of compounds, reflecting the flexibility in the chemical composition and crystal structure. Structures of perovskite compounds can be regarded as the stacking of close-packed $\mathrm{AO}_{3}$ layers and the filling of subsequent octahedral sites by B-site ions. The difference in the stacking sequence changes the way of linkage of $\mathrm{BO}_{6}$ octahedra: the corner-sharing $\mathrm{BO}_{6}$ in the cubic perovskite ( $3 \mathrm{~L}$ : three-layer) with $a b c \ldots$ sequence, the face-sharing $\mathrm{BO}_{6}$ in $2 \mathrm{~L}$-perovskite (2L: two-layer) with $a b \ldots$ sequence, and mixed linkages between the corner- and face-sharing in various intergrowth structures [1].

The 6L-perovskites $\mathrm{Ba}_{3} \mathrm{MM}_{2}{ }_{2} \mathrm{O}_{9}(\mathrm{M}=$ alkali metals, alkaline earth elements, $3 \mathrm{~d}$ transition metals, lanthanides; $M^{\prime}=\mathrm{Ru}$, Ir) have been investigated [2-29]. In this structure, two $\mathrm{M}^{\prime} \mathrm{O}_{6}$ octahedra are connected by face-sharing and form an $\mathrm{M}_{2}{ }_{2} \mathrm{O}_{9}$ dimer. These dimers and $\mathrm{MO}_{6}$ octahedra are placed alternately; thus, 6-layer (6L) structure is generated. The stacking sequence of $\mathrm{AO}_{3}$ layers is $a b a c b c \ldots$. For many of these compounds, an antiferromagnetic spin-pairing occurs in the $\mathrm{M}_{2}^{\prime} \mathrm{O}_{9}$ dimer even at room temperature. In addition, the $\mathrm{Ba}_{3} \mathrm{MM}_{2}{ }_{2} \mathrm{O}_{9}$ compounds show magnetic transitions at low temperatures, which originates from the magnetic interaction between $\mathrm{M}$ and $\mathrm{M}$ ' ions.

Then, we focused our attention on new quadruple perovskite compounds $\mathrm{Ba}_{4} \mathrm{LnRu}_{3} \mathrm{O}_{12}(\mathrm{Ln}$ $=$ lanthanides) in which the ratio of $\mathrm{Ln}: \mathrm{Ru}$ is 1:3. In the $\mathrm{Ba}_{4} \mathrm{LnRu}_{3} \mathrm{O}_{12}$, three $\mathrm{RuO}_{6}$ octahedra are face-shared, forming a $\mathrm{Ru}_{3} \mathrm{O}_{12}$ trimer, and we thought that peculiar magnetic behavior due to new alignment of the $\mathrm{Ln}$ and $\mathrm{Ru}$ ions should be observed [30]. In the $\mathrm{Ba}_{3} \mathrm{LnRu}_{2} \mathrm{O}_{9}$, the ground state of the total spin of the isolated $\mathrm{Ru}_{2} \mathrm{O}_{9}$ dimer may be zero, i.e., $S_{\text {total }}=S_{1}+S_{2}=0$, for the case that the antiferromagnetic coupling exists between the $\mathrm{Ru}$ ions. On the other hand, in the case of $\mathrm{Ba}_{4} \mathrm{LnRu}_{3} \mathrm{O}_{12}$ compounds, the total magnetic moment of the $\mathrm{Ru}_{3} \mathrm{O}_{12}$ trimer does not disappear as far as three $\mathrm{Ru}$ ions are equivalent. The results of the magnetic susceptibility and specific heat measurements are that although no long-range magnetic ordering of $\mathrm{Ru}^{4+}$ ions was 
found for the $6 \mathrm{~L}$-perovskite $\mathrm{Ba}_{3} \mathrm{TbRu}_{2} \mathrm{O}_{9}, \mathrm{Ba}_{4} \mathrm{TbRu}_{3} \mathrm{O}_{12}$ showed an antiferromagnetic transition at $24 \mathrm{~K}$, which is due to the relatively strong magnetic interaction between $\mathrm{Tb}^{4+}$ ions and $\mathrm{Ru}_{3} \mathrm{O}_{12}$ trimer via the $\mathrm{Tb}-\mathrm{O}-\mathrm{Ru}$ pathway owing to an uncancelled magnetic moment in the $\mathrm{Ru}_{3} \mathrm{O}_{12}$ trimer.

In this work, we challenged preparing new iridium-containing quadruple perovskite compounds $\mathrm{Ba}_{4} \mathrm{LnIr}_{3} \mathrm{O}_{12}$. Battle et al. reported that the compounds $\mathrm{Ba}_{4} \mathrm{MIr}_{3} \mathrm{O}_{12}(\mathrm{M}=\mathrm{Li}, \mathrm{Na}, \mathrm{Mg}$, $\mathrm{Y}, \mathrm{Lu}, \mathrm{Zr}$, and $\mathrm{Ce}$ ) adopted the $6 \mathrm{~L}-$ perovskite structure, i.e., the face-sharing octahedral were occupied solely by Ir atoms, and the corner-sharing octahedral were occupied statistically by the remaining Ir and the $M$ atoms in a 1:3 ratio [31]. Although these $M$ atoms have different charges and sizes, all the $\mathrm{Ba}_{4} \mathrm{MIr}_{3} \mathrm{O}_{12}$ compounds had the same crystal structure. We could introduce the Ir atoms in a 3:1 ratio with lanthanides into the B-site of the perovskite, and stabilize the fully ordered $12 \mathrm{~L}$ perovskite structure. In order to elucidate the properties of $\operatorname{Ir}_{3} \mathrm{O}_{12}$ trimer, the magnetic properties of these $\mathrm{Ba}_{4} \mathrm{LnIr}_{3} \mathrm{O}_{12}$ compounds were investigated.

\section{Experimental}

\subsection{Synthesis}

Polycrystalline samples of $\mathrm{Ba}_{4} \mathrm{LnIr}_{3} \mathrm{O}_{12}(\mathrm{Ln}=\mathrm{La}-\mathrm{Nd}, \mathrm{Sm}-\mathrm{Lu})$ were prepared by the standard solid-state reaction. $\mathrm{BaIrO}_{3}, \mathrm{BaLnO}_{3}(\mathrm{Ln}=\mathrm{Ce}, \mathrm{Pr}, \mathrm{Tb}), \mathrm{BaO}, \mathrm{BaO}_{2}$, and $\mathrm{Ln}_{2} \mathrm{O}_{3}(\mathrm{Ln}=$ $\mathrm{La}, \mathrm{Pr}, \mathrm{Sm}-\mathrm{Gd}, \mathrm{Dy}-\mathrm{Lu}$ ) were used as starting materials. Among them, $\mathrm{La}_{2} \mathrm{O}_{3}$ and $\mathrm{Nd}_{2} \mathrm{O}_{3}$ absorb moistures in air and easily form lanthanide hydroxides $\operatorname{Ln}(\mathrm{OH})_{3}$. Then, these oxides were heated at $900{ }^{\circ} \mathrm{C}$ for $12 \mathrm{~h}$ so as to decompose into $\mathrm{Ln}_{2} \mathrm{O}_{3}$ before use. It is known that both the ternary oxides $\mathrm{BaIrO}_{3}$ and $\mathrm{BaLnO}_{3}$ are formed with stoichiometric compositions. $\mathrm{BaIrO}_{3}$ was prepared by the solid state reaction of $\mathrm{BaCO}_{3}$ and $\mathrm{IrO}_{2}$ at $900{ }^{\circ} \mathrm{C}$ for $12 \mathrm{~h}$ and at $1100{ }^{\circ} \mathrm{C}$ for $12 \mathrm{~h}[32,33]$. $\mathrm{BaLnO}_{3}(\mathrm{Ln}=\mathrm{Ce}, \mathrm{Pr}, \mathrm{Tb})$ were obtained by heating mixtures of $\mathrm{BaCO}_{3}$ and $\mathrm{CeO}_{2}\left(\right.$ or $\mathrm{Pr}_{6} \mathrm{O}_{11}$, $\left.\mathrm{Tb}_{4} \mathrm{O}_{7}\right)$ in an oxygen flowing atmosphere [34-36]. These starting materials were weighed out in the appropriate metal ratio, and well mixed in an agate mortar. The mixtures were pressed 
into pellets and enclosed with platinum tubes, and they were sealed in evacuated silica tubes. Then, they were fired at $1250^{\circ} \mathrm{C}$ for $36 \mathrm{~h}$.

The obtained phases were identified by powder X-ray diffraction (XRD) measurements. Impurity phases such as $6 \mathrm{~L}$-perovskite $\mathrm{Ba}_{3} \mathrm{LnIr}_{2} \mathrm{O}_{9}[25,26]$ were formed due to the sublimation of Ba oxides and Ir oxides. In order to decrease such impurity phases, the excess amount ( $30 \%)$ of $\mathrm{BaIrO}_{3}[32,33]$ was added during sample preparation.

\subsection{X-ray diffraction analysis}

Powder X-ray diffraction profiles were measured using a Rigaku Multi-Flex diffractometer with $\mathrm{Cu}-\mathrm{K} \alpha$ radiation equipped with a curved graphite monochromator. The data were collected by step-scanning in the angle range of $10^{\circ} \leq 2 \theta \leq 120^{\circ}$ at a $2 \theta$ step-size of $0.02^{\circ}$. The X-ray diffraction data were analyzed by the Rietveld technique, using the programs RIETAN2000 [37].

\subsection{Magnetic susceptibility measurements}

The temperature-dependence of the magnetic susceptibility was measured in an applied field of $0.1 \mathrm{~T}$ over the temperature range of $1.8 \mathrm{~K} \leq T \leq 400 \mathrm{~K}$, using a SQUID magnetometer (Quantum Design, MPMS5S). The susceptibility measurements were performed under both zero-field-cooled (ZFC) and field-cooled (FC) conditions. The former was measured upon heating the sample to $400 \mathrm{~K}$ under the applied magnetic field of $0.1 \mathrm{~T}$ after zero-field cooling to $1.8 \mathrm{~K}$. The latter was measured upon cooling the sample from 400 to $1.8 \mathrm{~K}$ at $0.1 \mathrm{~T}$.

\subsection{Specific heat measurements}

Specific heat measurements were performed using a relaxation technique by a commercial heat capacity measuring system (Quantum Design, PPMS) in the temperature range of 1.8-400 $\mathrm{K}$. The sintered sample in the form of a pellet was mounted on a thin alumina plate with Apiezon grease for better thermal contact. 


\section{Results and Discussion}

\subsection{Synthesis and analysis of the structure}

We succeeded in synthesizing new perovskite-related compounds $\mathrm{Ba}_{4} \mathrm{LnIr}_{3} \mathrm{O}_{12}$ ( $\mathrm{Ln}=$ $\mathrm{La}-\mathrm{Nd}, \mathrm{Sm}-\mathrm{Lu}$ ). Figure 1 shows the powder $\mathrm{X}$-ray diffraction profile of $\mathrm{Ba}_{4} \mathrm{NdIr}_{3} \mathrm{O}_{12}$ as an example. To analyze the XRD diffraction profile, we used the crystal structure data of $\mathrm{Ba}_{4} \mathrm{LnRu}_{3} \mathrm{O}_{12}$ as the initial structural model. The $\mathrm{Ba}_{4} \mathrm{LnRu}_{3} \mathrm{O}_{12}$ for $\mathrm{Ln}=\mathrm{Tb}$ - $\mathrm{Lu}$ have a hexagonal unit cell with space group $R-3 m$ (No.166), while those for $\mathrm{Ln}=\mathrm{La}-\mathrm{Nd}, \mathrm{Sm}-\mathrm{Gd}$ have a monoclinic unit cell with space group $C 2 / m$ (No.12) [30]. In the case that the space group $R-3 m$ were applied, the X-ray diffraction lines observed at $2 \theta=27^{\circ}$ and $30^{\circ}$, for example, should not be split. However, experimental results show that each of these diffraction lines is split into two diffraction lines, as shown in the inset of Fig. 1. All the $\mathrm{Ba}_{4} \mathrm{LnIr}_{3} \mathrm{O}_{12}$ compounds prepared in this study were indexed with a monoclinic 12L-perovskite type cell with space group $C 2 / \mathrm{m}$.

Figure 2 shows the crystal structure of $\mathrm{Ba}_{4} \mathrm{LnIr}_{3} \mathrm{O}_{12}$. Three $\mathrm{IrO}_{6}$ octahedra are connected to each other by face-sharing and form an $\mathrm{Ir}_{3} \mathrm{O}_{12}$ trimer. $\mathrm{The} \mathrm{Ir}_{3} \mathrm{O}_{12}$ trimers and $\mathrm{LnO}_{6}$ octahedra are alternately linked by corner-sharing. As shown in this figure, perovskite-type structure with 12 layers is formed (the stacking sequence: ababcacabcbc...). Similar structures have been reported for $\mathrm{Ba}_{4} \mathrm{ZrRu}_{3} \mathrm{O}_{12}$ [38] and $\mathrm{Ba}_{4} \mathrm{LnMn}_{3} \mathrm{O}_{12}(\mathrm{Ln}=\mathrm{Ce}$, Pr) [39]. The distances between Ir atoms in the $\operatorname{Ir}_{3} \mathrm{O}_{12}$ trimer are determined to be $2.48 \sim 2.60 \AA$, which are much shorter than double the metallic radius of $\operatorname{Ir}(2.72 \AA)$ [40]. This means that a strong interaction between $\operatorname{Ir}$ ions should exist in the trimer. The oxidation state of $\mathrm{Ln}$ and $\mathrm{Ir}$ are both tetravalent for $\mathrm{Ln}=\mathrm{Ce}$, $\mathrm{Pr}$, Tb compounds $\left(\mathrm{Ba}_{4} \mathrm{Ln}^{4+} \mathrm{Ir}_{3}^{4+} \mathrm{O}_{12}\right)$, and $\mathrm{Ln}$ ions are in the trivalent state and the mean oxidation state of Ir ions is +4.33 for other compounds $\left(\mathrm{Ba}_{4} \mathrm{Ln}^{3+} \operatorname{Ir}^{4.33+}{ }_{3} \mathrm{O}_{12}\right)$.

Figure 3 shows the variation of lattice parameters with the ionic radius of $\mathrm{Ln}^{3+}$. Except for the compounds having the $\mathrm{Ln}^{4+}$ ion $(\mathrm{Ln}=\mathrm{Ce}, \mathrm{Pr}$, and $\mathrm{Tb})$, the lattice parameters $a, b$, and $c$ monotonously increase with the $\mathrm{Ln}^{3+}$ ionic radius. The angle $\beta$ increases from $90^{\circ}$ with the $\mathrm{Ln}^{3+}$ ionic radius, which indicates that with increasing the size of the $\mathrm{Ln}^{3+}$ ion, the crystal structures 
of $\mathrm{Ba}_{4} \mathrm{LnIr}_{3} \mathrm{O}_{12}$ are more distorted because of the larger difference in the ionic radius between Ln and Ir ions.

\subsection{Magnetic properties}

3.2.1. $\mathrm{Ba}_{4} \mathrm{Ln}^{3+} \mathrm{Ir}^{4.33+}{ }_{3} \mathrm{O}_{12}(\mathrm{Ln}=\mathrm{La}, \mathrm{Nd}-\mathrm{Gd}, \mathrm{Dy}-\mathrm{Lu})$

Figures 4 (a) and (b) show the temperature dependence of the reciprocal magnetic susceptibility for $\mathrm{Ba}_{4} \mathrm{LnIr}_{3} \mathrm{O}_{12}(\mathrm{Ln}=\mathrm{La}, \mathrm{Nd}-\mathrm{Gd}$, Dy-Lu). These compounds are paramagnetic down to $1.8 \mathrm{~K}$. In the temperature range where the Curie-Weiss law holds, the effective magnetic moments were determined and they are listed in Table 1. The effective magnetic moments determined for $\mathrm{Ba}_{4} \operatorname{LnIr}_{3} \mathrm{O}_{12}\left(\mu_{\text {eff }}\right)$ are close to the magnetic moments of $\operatorname{Ln}^{3+}$ ions $\left(\mu_{\mathrm{Ln}}\right)$, i.e., the contribution of the trimer $\operatorname{Ir}^{4.33+}{ }_{3} \mathrm{O}_{12}$ to the magnetic properties of $\mathrm{Ba}_{4} \mathrm{LnIr}_{3} \mathrm{O}_{12}$ is negligible. This result can be understood in the following.

The distances between $\mathrm{Ir}$ atoms in the $\mathrm{Ir}_{3} \mathrm{O}_{12}$ trimer are 2.48 2.60 $\AA$. The short Ir-Ir interatomic distances in the $\operatorname{Ir}_{3} \mathrm{O}_{12}$ trimer suggest the overlap of metal d orbitals having lobes along the threefold symmetry axis, which means the formation of molecular orbitals in the $\mathrm{Ir}_{3} \mathrm{O}_{12}$ trimer. The electronic structure of $\mathrm{Ru}_{3} \mathrm{Cl}_{12}$ with $D_{3 \mathrm{~d}}$ point symmetry has been described [41]. The energy scheme of $\operatorname{Ir}_{3} \mathrm{O}_{12}$ in the $\mathrm{Ba}_{4} \mathrm{LnIr}_{3} \mathrm{O}_{12}$ should be similar to the case of $\mathrm{Ru}_{3} \mathrm{Cl}_{12}$, but the degenerated energy levels are expected to be split into more levels due to the monoclinic distortion of the $\operatorname{Ir}_{3} \mathrm{O}_{12}$ trimer and to the spin-orbit coupling of the $5 \mathrm{~d}$ electrons ( $\mathrm{Ir}$ ions). The electronic configuration of the $\mathrm{Ir}^{4.33+}{ }_{3} \mathrm{O}_{12}$ trimer (the number of $5 d$ electrons is 14 ) with $D_{3 \mathrm{~d}}$ point symmetry is $\left(a_{1 \mathrm{~g}}\right)^{2}\left(e_{\mathrm{g}}\right)^{4}\left(a_{2 \mathrm{u}}\right)^{2}\left(e_{\mathrm{u}}\right)^{4}\left(e_{\mathrm{g}}\right)^{2}$. Figure 5 illustrates the schematic energy level diagrams for the Ir-Ir interactions in (a) $\mathrm{Ir}^{4.33+}{ }_{3} \mathrm{O}_{12}$ and (b) $\mathrm{Ir}^{4+}{ }_{3} \mathrm{O}_{12}$. The highest occupied $e_{\mathrm{g}}$ orbital of the $\operatorname{Ir}_{3} \mathrm{O}_{12}$ trimer should be split into two singlets by the monoclinic distortion, which causes the $S=$ 0 ground state of the filled HOMO level. Therefore, the $\operatorname{Ir}^{4.33+}{ }_{3} \mathrm{O}_{12}$ trimer does not contribute to the magnetic properties of $\mathrm{Ba}_{4} \mathrm{LnIr}_{3} \mathrm{O}_{12}\left(\mathrm{Ln}=\mathrm{La}, \mathrm{Nd}-\mathrm{Gd}\right.$, Dy-Lu), and both $\mathrm{Ba}_{4} \mathrm{LaIr}_{3} \mathrm{O}_{12}$ and $\mathrm{Ba}_{4} \mathrm{LuIr}_{3} \mathrm{O}_{12}$ are diamagnetic. 


\subsection{2. $\mathrm{Ba}_{4} \mathrm{Ln}^{4+} \mathrm{Ir}^{4+}{ }_{3} \mathrm{O}_{12}(\mathrm{Ln}=\mathrm{Ce}, \mathrm{Pr}, \mathrm{Tb})$}

The temperature dependence of the magnetic susceptibility and the reciprocal susceptibility for $\mathrm{Ba}_{4} \mathrm{CeIr}_{3} \mathrm{O}_{12}$ is shown in Figs. 6 (a) and (b), respectively. The same temperature dependence of the susceptibility and the reciprocal susceptibility for $\mathrm{Ba}_{4} \operatorname{PrIr}_{3} \mathrm{O}_{12}$ and $\mathrm{Ba}_{4} \operatorname{TbIr}_{3} \mathrm{O}_{12}$ is depicted in Figs. 7 and 9, respectively. From the Curie-Weiss fitting in the temperature range between 300 and $400 \mathrm{~K}$, the effective magnetic moments of $\mathrm{Ba}_{4} \mathrm{LnIr}_{3} \mathrm{O}_{12}$ with $\mathrm{Ln}=\mathrm{Ce}$, $\mathrm{Pr}$, and $\mathrm{Tb}$ are obtained to be $1.24,2.94$, and $8.02 \mu_{\mathrm{B}}$, respectively (Table 1 ). When the magnetic ions in these compounds are magnetically independent, the effective magnetic moments of $\mathrm{Ba}_{4} \mathrm{LnIr}_{3} \mathrm{O}_{12}$ should be calculated from the equation $\mu_{c a l}=\sqrt{{\mu_{L n^{4+}}{ }^{2}+3 \times \mu_{I r^{4+}}{ }^{2}}^{2}}$. However, the effective magnetic moments obtained experimentally are far below the calculated moments. We will discuss the magnetic behavior of $\operatorname{Ir}_{3}^{4+} \mathrm{O}_{12}$ trimer in the same way as the case of $\operatorname{Ir}^{4.33+}{ }_{3} \mathrm{O}_{12}$. The $\mathrm{Ir}_{3}^{4+}{ }_{3} \mathrm{O}_{12}$ trimer has fifteen $5 d$ electrons, and its electronic configuration is $\left(a_{1 \mathrm{~g}}\right)^{2}\left(e_{\mathrm{g}}\right)^{4}\left(a_{2 \mathrm{u}}\right)^{2}\left(e_{\mathrm{u}}\right)^{4}\left(e_{\mathrm{g}}\right)^{3}$, which should cause the $S=1 / 2$ ground state (see Fig. 5 (b)). In this case, the effective magnetic moments for $\mathrm{Ba}_{4} \mathrm{Ln}^{4+} \mathrm{Ir}^{4+}{ }_{3} \mathrm{O}_{12}(\mathrm{Ln}=\mathrm{Ce}, \mathrm{Pr}$, Tb) are calculated from the equation $\mu_{c a l}=\sqrt{{\mu_{L n^{4+}}{ }^{2}+\mu_{S=1 / 2}{ }^{2}}^{2}}$, and they are listed in Table 1. The effective magnetic moments of $\mathrm{Ba}_{4} \mathrm{LnIr}_{3} \mathrm{O}_{12}$ experimentally determined are almost in accordance with the calculated moments. The moment of $\mathrm{Ba}_{4} \mathrm{CeIr}_{3} \mathrm{O}_{12}$ is a little smaller than the expected value, which is due to existence of impurities such as $\mathrm{Ba}_{3} \mathrm{CeIr}_{2} \mathrm{O}_{9}$. The $\mathrm{Ba}_{3} \mathrm{CeIr}_{2} \mathrm{O}_{9}$ shows a very small effective magnetic moment, because the magnetic moments of Ir ions cancel each other in the $\mathrm{Ir}_{2} \mathrm{O}_{9}$ dimer [25]. In the following, magnetic properties of each $\mathrm{Ba}_{4} \mathrm{LnIr}_{3} \mathrm{O}_{12}(\mathrm{Ln}=\mathrm{Ce}, \mathrm{Pr}, \mathrm{Tb})$ compound at lower temperatures will be described.

\subsubsection{1. $\mathrm{Ba}_{4} \mathrm{CeIr}_{3} \mathrm{O}_{12}$}

Magnetic susceptibility measurements on $\mathrm{Ba}_{4} \mathrm{CeIr}_{3} \mathrm{O}_{12}$ show that an antiferromagnetic transition occurs at $10.5 \mathrm{~K}$ (see Fig. 6 (a)). On the other hand, ruthenium-containing compound $\mathrm{Ba}_{4} \mathrm{CeRu}_{3} \mathrm{O}_{12}$ is paramagnetic down to $1.8 \mathrm{~K}$ [30]. Since the tetravalent cerium ion is 
diamagnetic, the $S=1 / 2$ state of the $\mathrm{Ir}^{4+}{ }_{3} \mathrm{O}_{12}$ trimer is responsible for the antiferromagnetic transition of $\mathrm{Ba}_{4} \mathrm{CeIr}_{3} \mathrm{O}_{12}$. Specific heat measurements on $\mathrm{Ba}_{4} \mathrm{CeIr}_{3} \mathrm{O}_{12}$ also show a clear anomaly against temperature at $10.5 \mathrm{~K}$, indicating the occurrence of the long-range antiferromagnetic ordering at this temperature. Below $5 \mathrm{~K}$, the magnetic susceptibility of $\mathrm{Ba}_{4} \mathrm{CeIr}_{3} \mathrm{O}_{12}$ increases with decreasing temperature, which is probably due to the existence of small amount of paramagnetic impurities such as $\mathrm{Ba}_{3} \mathrm{CeIr}_{2} \mathrm{O}_{9}$. The $\mathrm{Ba}_{3} \mathrm{CeIr}_{2} \mathrm{O}_{9}$ is paramagnetic down to $1.8 \mathrm{~K}[25]$.

\subsubsection{2. $\mathrm{Ba}_{4} \mathrm{PrIr}_{3} \mathrm{O}_{12}$}

The results of the magnetic susceptibility measurements (Fig. 7 (a)) show that $\mathrm{Ba}_{4} \operatorname{PrIr}_{3} \mathrm{O}_{12}$ orders antiferromagnetically at $35 \mathrm{~K}$. Its transition temperature is higher than that of $\mathrm{Ba}_{4} \mathrm{CeIr}_{3} \mathrm{O}_{12}$. This reflects the fact that the $\mathrm{Pr}^{4+}$ ion contributes to the magnetic superexchange interaction between $\operatorname{Ir}^{4+}$ ions. This compound also shows the increase of magnetic susceptibility with decreasing temperature below $10 \mathrm{~K}$. This behavior is ascribed to the paramagnetic impurities such as $\mathrm{Ba}_{3} \operatorname{PrIr}_{2} \mathrm{O}_{9}$, which is paramagnetic down to $1.8 \mathrm{~K}$ [25].

In order to obtain detailed information about the low-temperature magnetic ordering, specific heat measurements were performed down to $1.8 \mathrm{~K}$. Figure 8 (a) shows the temperature dependence of the specific heat $\left(C_{\mathrm{p}}\right)$ divided by temperature $\left(C_{\mathrm{p}} / T\right)$ for $\mathrm{Ba}_{4} \operatorname{PrIr}_{3} \mathrm{O}_{12}$. A specific heat anomaly has been observed at $35 \mathrm{~K}$, which corresponds to the results by magnetic susceptibility measurements. This result indicates that the long range antiferromagnetic ordering occur at this temperature. To evaluate the magnetic contribution to the specific heat $\left(C_{\mathrm{mag}}\right)$, we have to subtract the contribution of lattice specific heat $\left(C_{\text {lat }}\right)$ from the total specific heat $\left(C_{\mathrm{mag}}\right.$ $=C_{\mathrm{p}}-C_{\text {lat }}$. The lattice specific heat was estimated by using the specific heat data of a diamagnetic compound $\mathrm{Ba}_{4} \mathrm{LuIr}_{3} \mathrm{O}_{12}$ (the dotted line of Fig. 8 (a)). Figure 8 (b) shows the temperature dependence of the magnetic specific heat divided by temperature $\left(C_{\text {mag }} / T\right)$. The magnetic entropy change due to the magnetic ordering of $\mathrm{Ba}_{4} \operatorname{PrIr}_{3} \mathrm{O}_{12}\left(S_{\text {mag }}\right)$ is calculated by the

relation $S_{\text {mag }}=\int\left(C_{\text {mag }} / T\right) d T$. Its temperature dependence is also shown in Fig. 8 (b). The total 
magnetic entropy change is obtained to be $8.7 \mathrm{~J} / \mathrm{mol} \mathrm{K}$.

The corresponding ruthenium-containing compound $\mathrm{Ba}_{4} \mathrm{PrRu}_{3} \mathrm{O}_{12}$ shows an antiferromagnetic transition at $2.4 \mathrm{~K}$, and its specific heat measurements indicated that the antiferromagnetic ordering is only due to the ground Kramers doublet of $^{\mathrm{Pr}^{4+}}$ ion [30]. The crystal structure of $\mathrm{Ba}_{4} \operatorname{PrIr}_{3} \mathrm{O}_{4}$ is the same with that of $\mathrm{Ba}_{4} \operatorname{PrRu}_{3} \mathrm{O}_{4}$. In a similar way, the ground Kramers doublet of $\operatorname{Pr}^{4+}$ ion in a low symmetric crystal field is responsible for the antiferromagnetic ordering of $\mathrm{Ba}_{4} \operatorname{PrIr}_{3} \mathrm{O}_{4}$. Therefore, its contribution to the magnetic entropy change is estimated to be $R \ln 2$. The magnetic entropy change due to the antiferromagnetic ordering of the $\operatorname{Ir}^{4+}{ }_{3} \mathrm{O}_{12}$ trimer $(S=1 / 2)$ is also calculated to be $R \ln 2$. Although the magnetic entropy change obtained experimentally $\left(S_{\mathrm{mag}}=\sim 8.7 \mathrm{~J} / \mathrm{mol} \mathrm{K}\right)$ is a little smaller than that calculated $2 R \ln 2(=11.52 \mathrm{~J} / \mathrm{mol} \mathrm{K})$, we can conclude that both the $4 \mathrm{f}$ electron of $\operatorname{Pr}^{4+}$ and the $5 \mathrm{~d}$ electron of $\mathrm{Ir}^{4+}$ contribute to the antiferromagnetic ordering of $\mathrm{Ba}_{4} \operatorname{PrIr}_{3} \mathrm{O}_{4}$.

\subsubsection{3. $\mathrm{Ba}_{4} \mathrm{TbIr}_{3} \mathrm{O}_{12}$}

Figure 9 (a) shows that $\mathrm{Ba}_{4} \mathrm{TbIr}_{3} \mathrm{O}_{12}$ orders antiferromagnetically at $16 \mathrm{~K}$. Below this temperature, the divergence between the ZFC and FC susceptibilities is observed, which indicates a small ferromagnetic moment. For compounds with low crystal symmetry such as monoclinic, a Dzyaloshinsky-Moriya (D-M) interaction can exist between the ordered magnetic moments, which results in the existence of a weak ferromagnetic moment associated with the antiferromagnetism. The increase of magnetic susceptibility with decreasing temperature below $5 \mathrm{~K}$ is probably due to the paramagnetic impurities such as $\mathrm{Ba}_{3} \operatorname{TbIr}_{2} \mathrm{O}_{9}$ and $\mathrm{Ba}_{2} \mathrm{TbIrO}_{6}[25,42]$. Figure 10 (a) shows the temperature dependence of the specific heat divided by temperature $\left(C_{\mathrm{p}} / T\right)$ for $\mathrm{Ba}_{4} \mathrm{TbIr}_{3} \mathrm{O}_{12}$. A clear $\lambda$-type specific heat anomaly has been observed at $16 \mathrm{~K}$, which indicates that the long range antiferromagnetic ordering occurs at this temperature. In the same way as the case for $\mathrm{Ba}_{4} \operatorname{PrIr}_{3} \mathrm{O}_{12}$, the magnetic specific heat $\left(C_{\text {mag }}\right)$ was evaluated by subtracting the specific heat of $\mathrm{Ba}_{4} \mathrm{LuIr}_{3} \mathrm{O}_{12}\left(C_{\text {lat }}\right)$ from the total specific heat $\left(C_{\text {mag }}=C_{\mathrm{p}}-C_{\text {lat }}\right)$. Figure 10 (b) shows the temperature dependence of the magnetic specific heat divided temperature 
$\left(C_{\text {mag }} / T\right)$. The magnetic entropy change for $\mathrm{Ba}_{4} \mathrm{TbIr}_{3} \mathrm{O}_{12}\left(S_{\text {mag }}\right)$ is also shown in the same figure, and it is obtained to be $\sim 18.5 \mathrm{~J} / \mathrm{mol} \mathrm{K}$. Magnetic entropy change due to the magnetic ordering of $\mathrm{Tb}^{4+}$ (the electronic configuration of $\mathrm{Tb}^{4+}$ : [Xe $] \mathrm{f}^{7}$; the $S=7 / 2$ ground state) is $R \ln (2 S+1)=$ 17.3 J/mol K. The experimental value is larger than this value, which indicates the contribution of the $\mathrm{Ir}^{4+}{ }_{3} \mathrm{O}_{12}$ trimer $(S=1 / 2)$ to the magnetic ordering at $16 \mathrm{~K}$. However, the experimental value is below the estimated total magnetic entropy change $(23.1 \mathrm{~J} / \mathrm{mol} \mathrm{K})$. The reason for this may be that the magnetic entropy is partially lost at higher temperatures because of the short range ordering. Similar smaller magnetic entropy change was reported for $\mathrm{Ba}_{4} \mathrm{TbRu}_{3} \mathrm{O}_{12}$, i.e., the magnetic entropy change due to the magnetic ordering of $\mathrm{Tb}^{4+}$ was $12.5 \mathrm{~J} / \mathrm{mol} \mathrm{K}$ [30].

\section{Summary}

New quadruple perovskites $\mathrm{Ba}_{4} \mathrm{LnIr}_{3} \mathrm{O}_{12}$ were prepared and they form the perovskite-type structure with 12 layers, in which $\mathrm{Ir}_{3} \mathrm{O}_{12}$ trimers and $\mathrm{LnO}_{6}$ octahedra are alternately linked by corner-sharing. For $\mathrm{Ln}=\mathrm{Ce}, \mathrm{Pr}$, and $\mathrm{Tb}$ compounds, an antiferromagnetic transition was observed at low temperatures, while the other compounds are paramagnetic down to $1.8 \mathrm{~K}$.

\section{Acknowledgement}

This work was supported by Grant-in-aid from the Ministry of Education, Science, Sports, and Culture of Japan. 


\section{References}

[1] J. M. Longo and J. A. Kafalas, J. Solid State Chem., 1, 103-108 (1969).

[2] R. C. Bryne and C. W. Moeller, J. Solid State Chem., 2, 228-235 (1970).

[3] J. Darriet, M. Drillon, G. Villeneuve, and P. Hagenmuller, J. Solid State Chem., 19, 213-220 (1976).

[4] H.-U. Schaller and S. Kemmler-Sack, Z. Anorg. Allg. Chem., 473, 178-188 (1981).

[5] I. Thumm, U. Treiber, and S. Kemmler-Sack, Z. Anorg. Allg. Chem., 477, 161-166 (1981).

[6] U. Treiber, S. Kemmler-Sack, A. Ehmann, H.-U. Schaller, E. Dürrschmidt, I. Thumm and H. Bader, Z. Anorg. Allg. Chem., 481, 143-152 (1981).

[7] H. W. Zandbergen and D. J. W. IJdo, Acta Crystallogr., C40, 919-922 (1984).

[8] D. Verdoes, H. W. Zandbergen, and D. J. W. IJdo, Acta Crystallogr., C41, 170-173 (1985).

[9] P. Lightfoot and P. D. Battle, J. Solid State Chem., 89, 174-183 (1990).

[10] P. D. Battle, S. H. Kim, and A. V. Powell, J. Solid State Chem., 101, 161-172 (1992).

[11] D. Schluter and H.-K. Müller-Buschbaum, J. Alloys Compd., 190, L43-L44 (1993).

[12] S. Scheske and H.-K. Müller-Buschbaum, J. Alloys Compd., 198, 173-176 (1993).

[13] M. Rath and H.-K. Müller-Buschbaum, J. Alloys Compd., 210, 119-123 (1994).

[14] S. H. Kim and P. D. Battle, J. Solid State Chem., 114, 174-183 (1995).

[15] P. D. Battle, J. G. Gore, R. C. Hollyman, and A. V. Powell, J. Alloys Compd., 218, $110-116(1995)$.

[16] D.-K. Jung, G. Demazeau, J. Etourneau, and M. A. Subramanian, Mater. Research Bull., 30, 113-123 (1995).

[17] J. T. Rijssenbeek, P. Matl, B. Batlogg, N. P. Ong, and R. J. Cava, Phys.Rev., 58, $10315-10318(1998)$

[18] J. T. Rijssenbeek, Q. Huang, R. W. Erwin, H. W. Zandbergen, and R. J. Cava, J. Solid 
State Chem., 146, 65-72 (1999).

[19] Y. Doi, Y. Hinatsu, Y. Shimojo, and Y. Ishii, J. Solid State Chem., 161, 113-120 (2001).

[20] Y. Doi, M. Wakeshima, Y. Hinatsu, A. Tobo, K. Ohoyama, and Y. Yamaguchi, J. Mater. Chem., 11, 3135-3140 (2001).

[21] K.E. Stitzer, M. D. Smith, W. R. Gemmill, and H.-C. zur Loye, J. Amer. Chem.Soc., 124, $13877-13885$ (2002).

[22] Y. Doi, K. Matsuhira, and Y. Hinatsu, J. Solid State Chem., 165, 317-323 (2002).

[23] Y. Doi and Y. Hinatsu, J. Mater. Chem., 12, 1792-1795 (2002).

[24] E. Quarez, M. Huve, F. Abraham, and O. Mentre, Solid State Sciences, 5, 951-963 (2003).

[25] Y. Doi and Y. Hinatsu, J. Phys.: Condens. Matter., 16, 2849-2860 (2004).

[26] Y. Doi and Y. Hinatsu, J. Solid State Chem., 177, 3239-3244 (2004).

[27] M. W. Lufaso and H.-C. zur Loye, Inorg. Chem., 44, 9143-9153 (2005).

[28] M. W. Lufaso and H.-C. zur Loye, Inorg. Chem., 44, 9154-9161 (2005).

[29] T. Sakamoto, Y. Doi, and Y. Hinatsu, J. Solid State Chem., 179, 2595-2601 (2006).

[30] Y. Shimoda, Y. Doi, Y. Hinatsu, and K. Ohoyama, Chem Mater, 20, 4512-4518 (2008).

[31] J. G. Gove and P. D. Battle, J. Mater. Chem., 6, 201-206 (1996).

[32] P.C. Donohue, L. Katz and R. Ward, Inorg. Chem., 4, 306-310 (1965).

[33] T. Siegrist, B. L. Chamberland, J. Less-Common Metals, 170, 93-99 (1991).

[34] Y. Hinatsu and N. Edelstein, J. Alloys Compd., 250, 400-404 (1997).

[35] M. Itoh and Y. Hinatsu, J. Alloys Compd., 264, 119-124 (1998).

[36] K. Tezuka, Y. Hinatsu, Y. Shimojo, and Y. Morii, J. Phys.: Condens. Matter., 10, 11703-11712 (1998).

[37] F. Izumi and T. Ikeda, Mater. Sci. Forum, 321-324, 198-203 (2000).

[38] C. H. De Vreugd, H. W. Zandbergen, and D. J. W. IJdo, Acta Crystallogr., C40, 1987-1989 (1984). 
[39] A. F. Fuentes, K. Boulahya, and U. Amador, J. Solid State Chem., 177, 714-720 (2004).

[40] A. F. Wells, Structural inorganic chemistry $5^{\text {th }}$ Ed., Oxford Clarendon Press., (1984).

[41] B. E. Bursten, F. A. Cotton, and A. Fang, Inorg. Chem., 22, 2127-2133 (1983).

[42] M. Wakeshima, D. Harada, and Y. Hinatsu, J. Mater. Chem., 10, 419-422 (2000). 


\section{Figure captions}

Fig. 1 X-ray diffraction profiles of $\mathrm{Ba}_{4} \mathrm{NdIr}_{3} \mathrm{O}_{12}$. The calculated and observed profiles are shown on the top solid line and cross markers, respectively. The vertical marks in the middle show positions calculated for Bragg reflections. The lower trace is a plot of the difference between calculated and observed intensities. The inset shows the profiles between $25^{\circ} \leq 2 \theta \leq 32^{\circ}$. The diffraction lines are indexed with a monoclinic 12L-perovskite type cell.

Fig. 2 The schematic crystal structure of $\mathrm{Ba}_{4} \mathrm{LnIr}_{3} \mathrm{O}_{12}$.

Fig. 3 The variation of lattice parameters for $\mathrm{Ba}_{4} \mathrm{LnIr}_{3} \mathrm{O}_{12}$ against the ionic radius of $\mathrm{Ln}^{3+}$.

Fig. 4 (a) Temperature dependence of the reciprocal magnetic susceptibilities for $\mathrm{Ba}_{4} \mathrm{LnIr}_{3} \mathrm{O}_{12}$ $(\mathrm{Ln}=\mathrm{Nd}, \mathrm{Tm}, \mathrm{Yb})$. The solid line is the Curie-Weiss fitting.

(b) Temperature dependence of the magnetic susceptibilities for $\mathrm{Ba}_{4} \mathrm{LnIr}_{3} \mathrm{O}_{12}(\mathrm{Ln}=\mathrm{Gd}$, Dy-Er). The solid line is the Curie-Weiss fitting.

Fig. 5 Schematic energy level diagrams for (a) $\mathrm{Ir}^{4.33+}{ }_{3} \mathrm{O}_{12}$ trimer and (b) $\mathrm{Ir}^{4+}{ }_{3} \mathrm{O}_{12}$ trimer.

Fig. 6 (a) Temperature dependence of the magnetic susceptibilities for $\mathrm{Ba}_{4} \mathrm{CeIr}_{3} \mathrm{O}_{12}$. The inset shows the magnetic susceptibilities at low temperatures.

(b) The reciprocal magnetic susceptibility against temperature. The solid line is the Curie-Weiss fitting.

Fig. 7 (a) Temperature dependence of the magnetic susceptibilities for $\mathrm{Ba}_{4} \operatorname{PrIr}_{3} \mathrm{O}_{12}$. The inset shows the magnetic susceptibilities at low temperatures.

(b) The reciprocal magnetic susceptibility against temperature. The solid line is the Curie-Weiss fitting.

Fig. 8 Temperature dependence of (a) the specific heat divided by temperature $\left(C_{\mathrm{p}} / T\right)$ and (b) the magnetic specific heat divided by temperature $\left(C_{\mathrm{mag}} / T\right)$ and the magnetic entropy $\left(S_{\text {mag }}\right)$ for $\mathrm{Ba}_{4} \mathrm{PrIr}_{3} \mathrm{O}_{12}$.

Fig. 9 (a) Temperature dependence of the magnetic susceptibilities for $\mathrm{Ba}_{4} \mathrm{TbIr}_{3} \mathrm{O}_{12}$. The 
inset shows the magnetic susceptibilities at low temperatures.

(b) The reciprocal magnetic susceptibility against temperature. The solid line is the Curie-Weiss fitting.

Fig. 10 Temperature dependence of (a) the specific heat divided by temperature $\left(C_{\mathrm{p}} / T\right)$ and (b) the magnetic specific heat divided by temperature $\left(C_{\mathrm{mag}} / T\right)$ and the magnetic entropy $\left(S_{\text {mag }}\right)$ for $\mathrm{Ba}_{4} \mathrm{TbIr}_{3} \mathrm{O}_{12}$. 


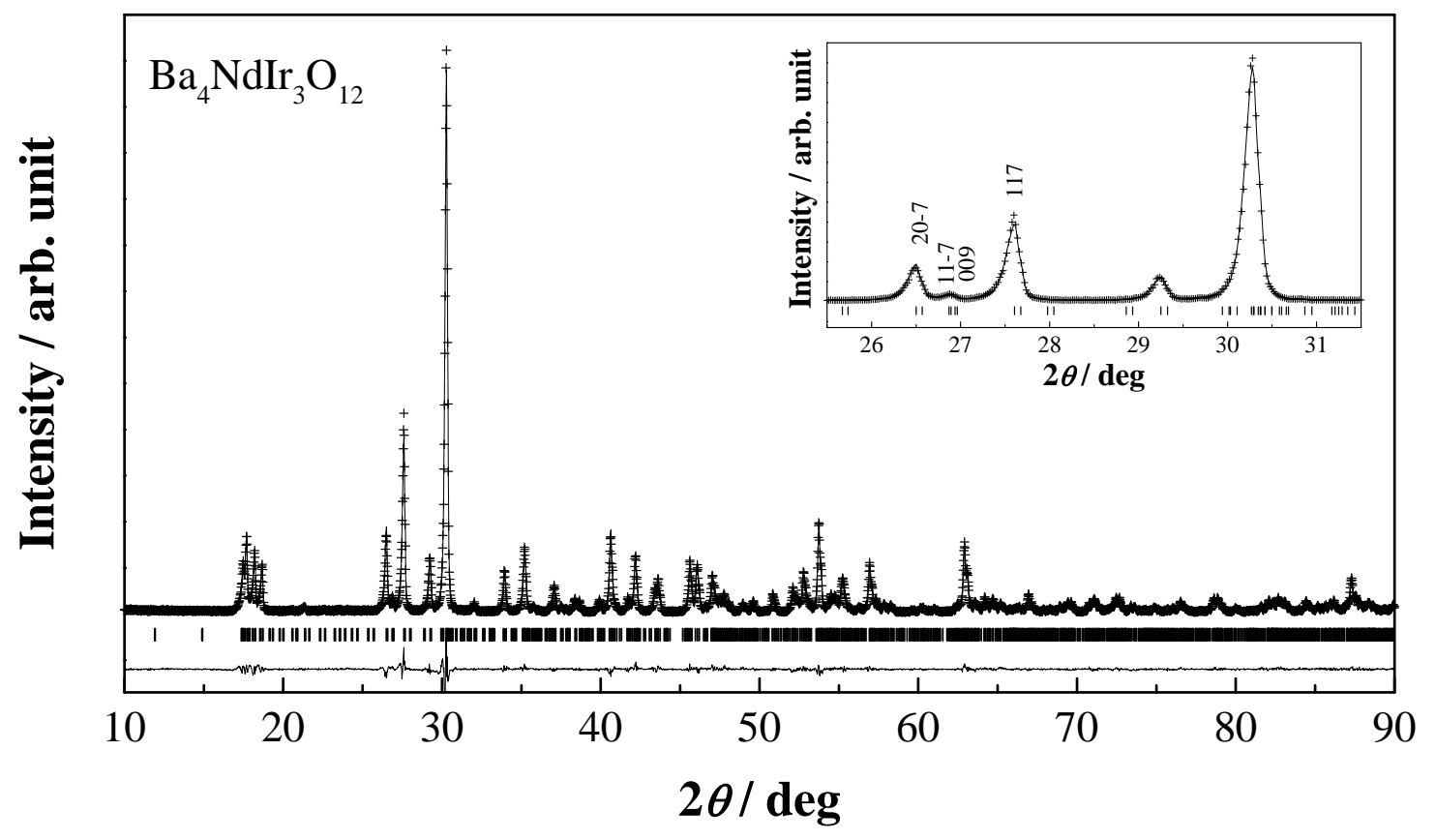

Fig. 1 


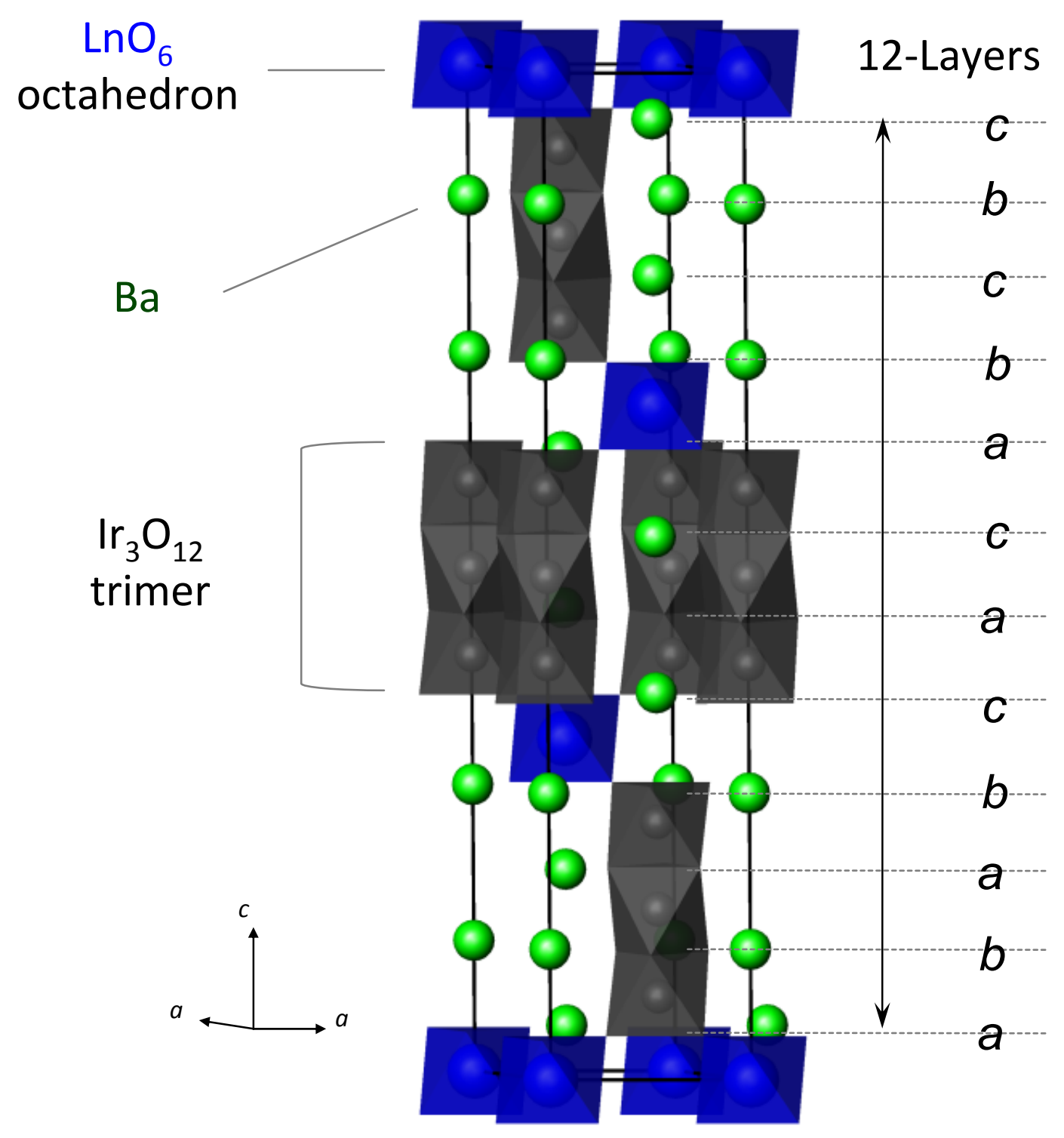

Fig.2 

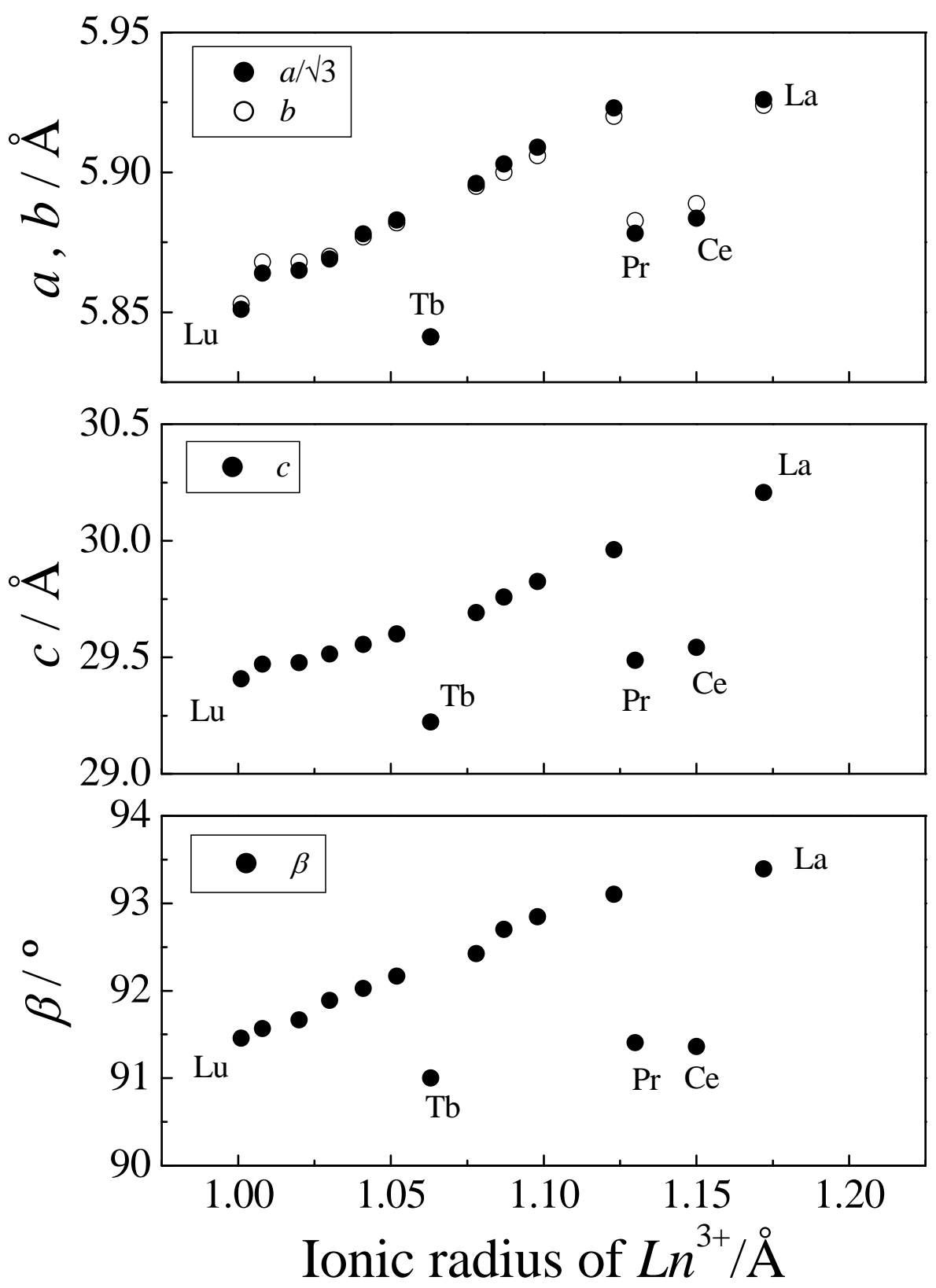

Fig.3 
(a)

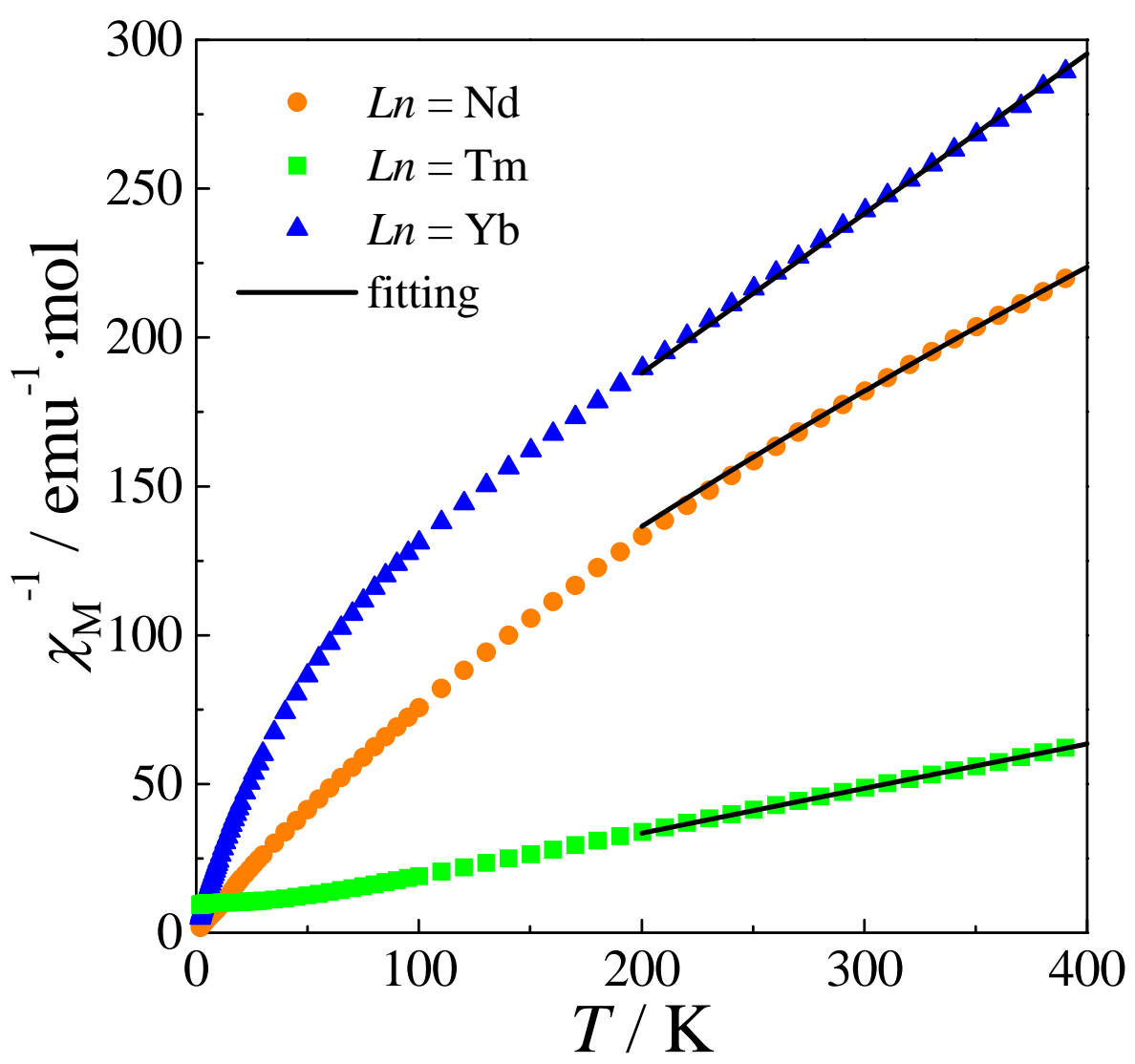

(b)

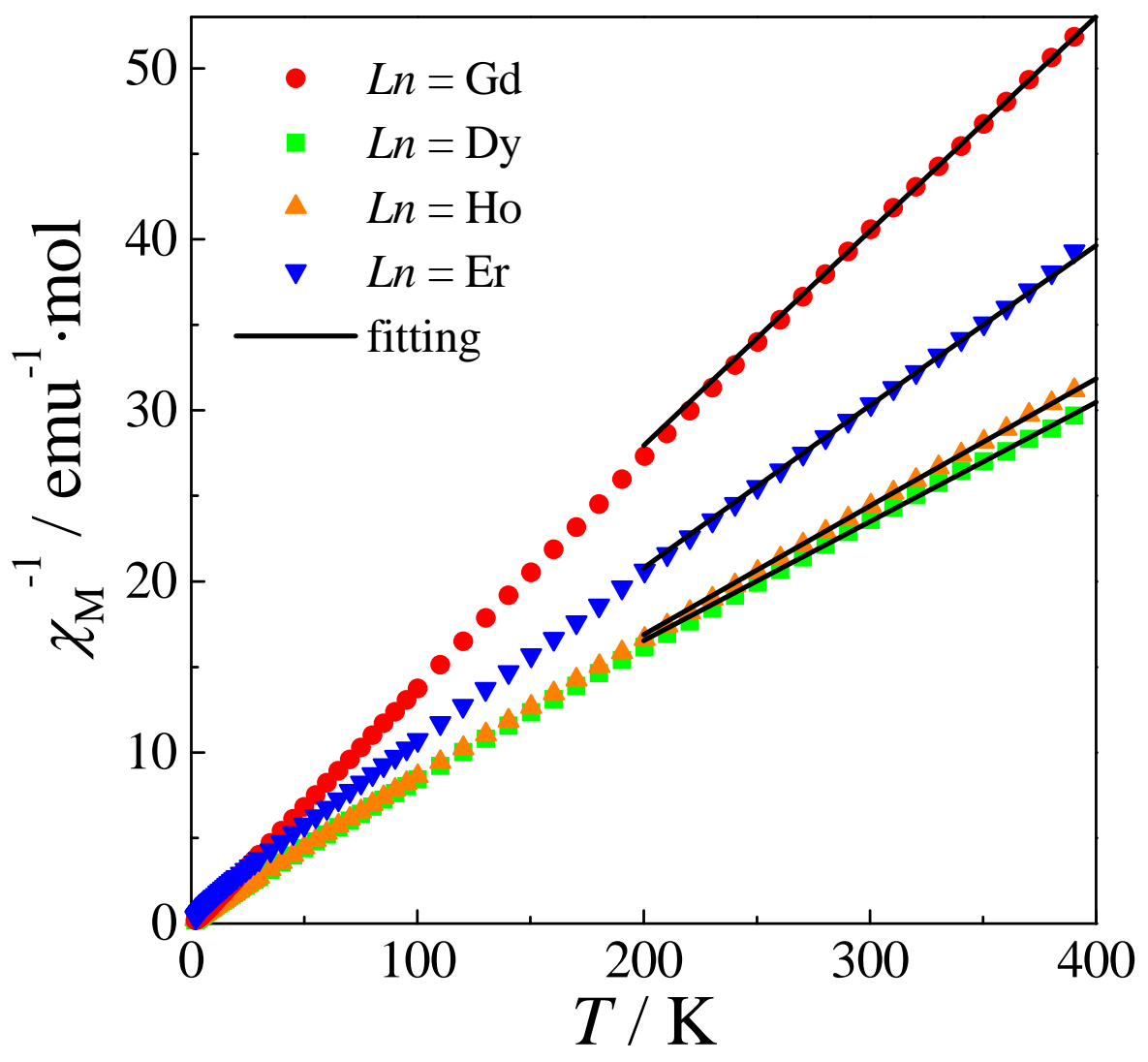

Fig.4 
(a)

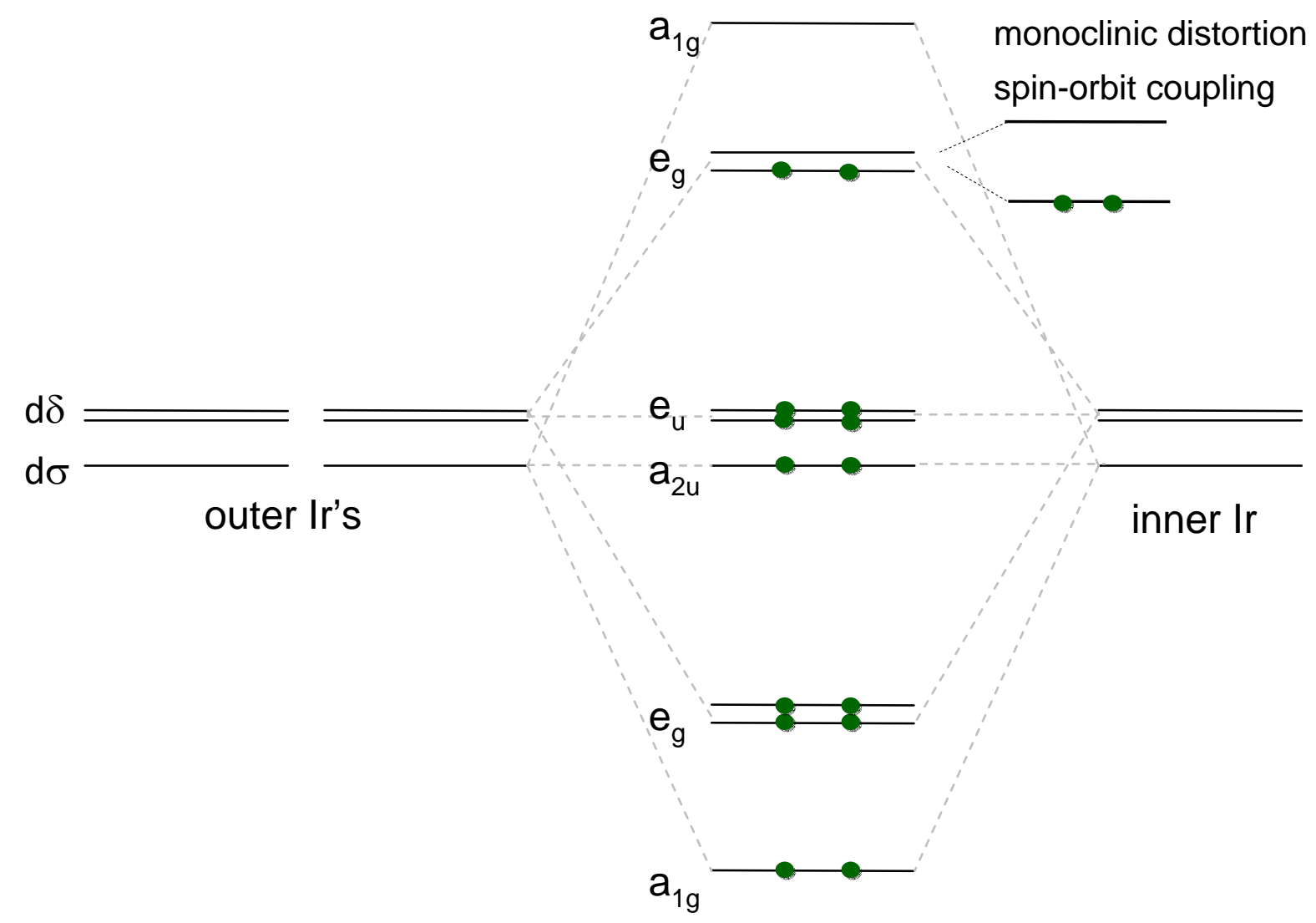

(b)
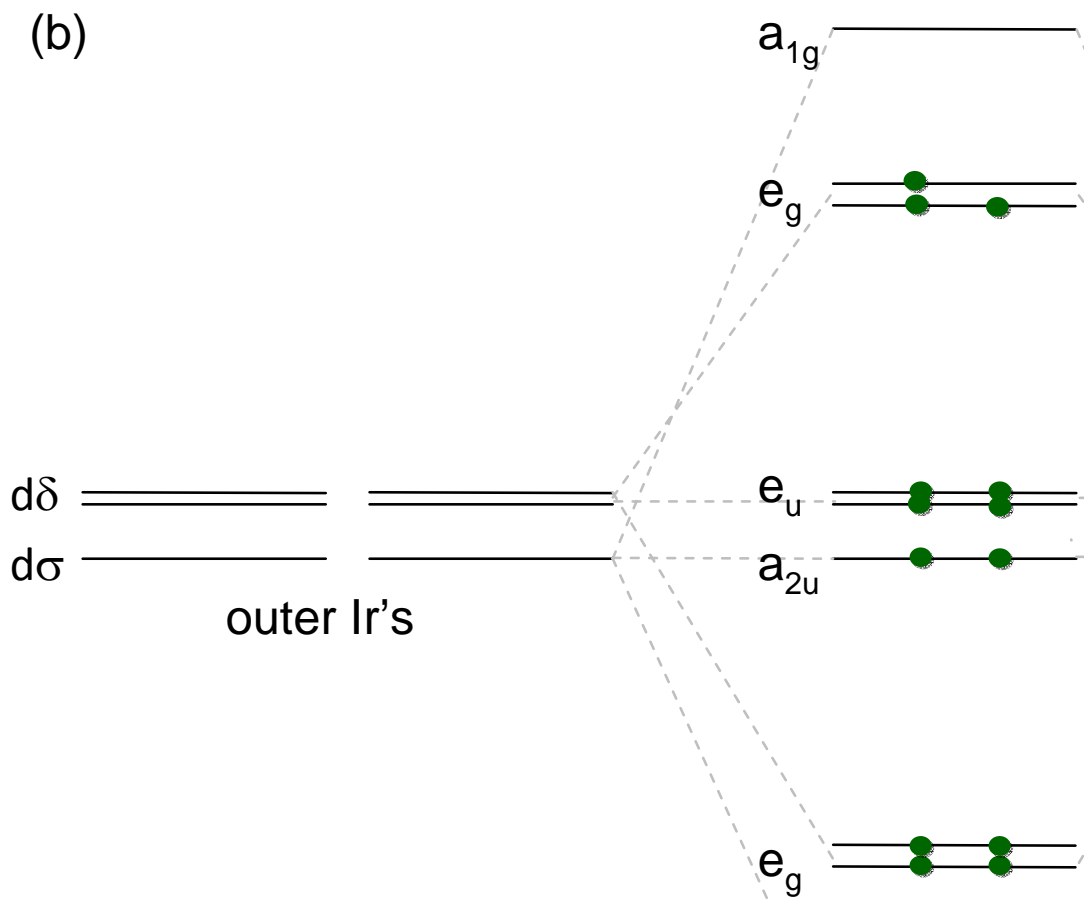

$a_{1 g}$

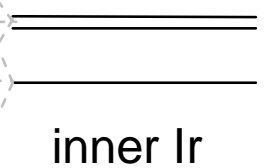

Fig. 5 


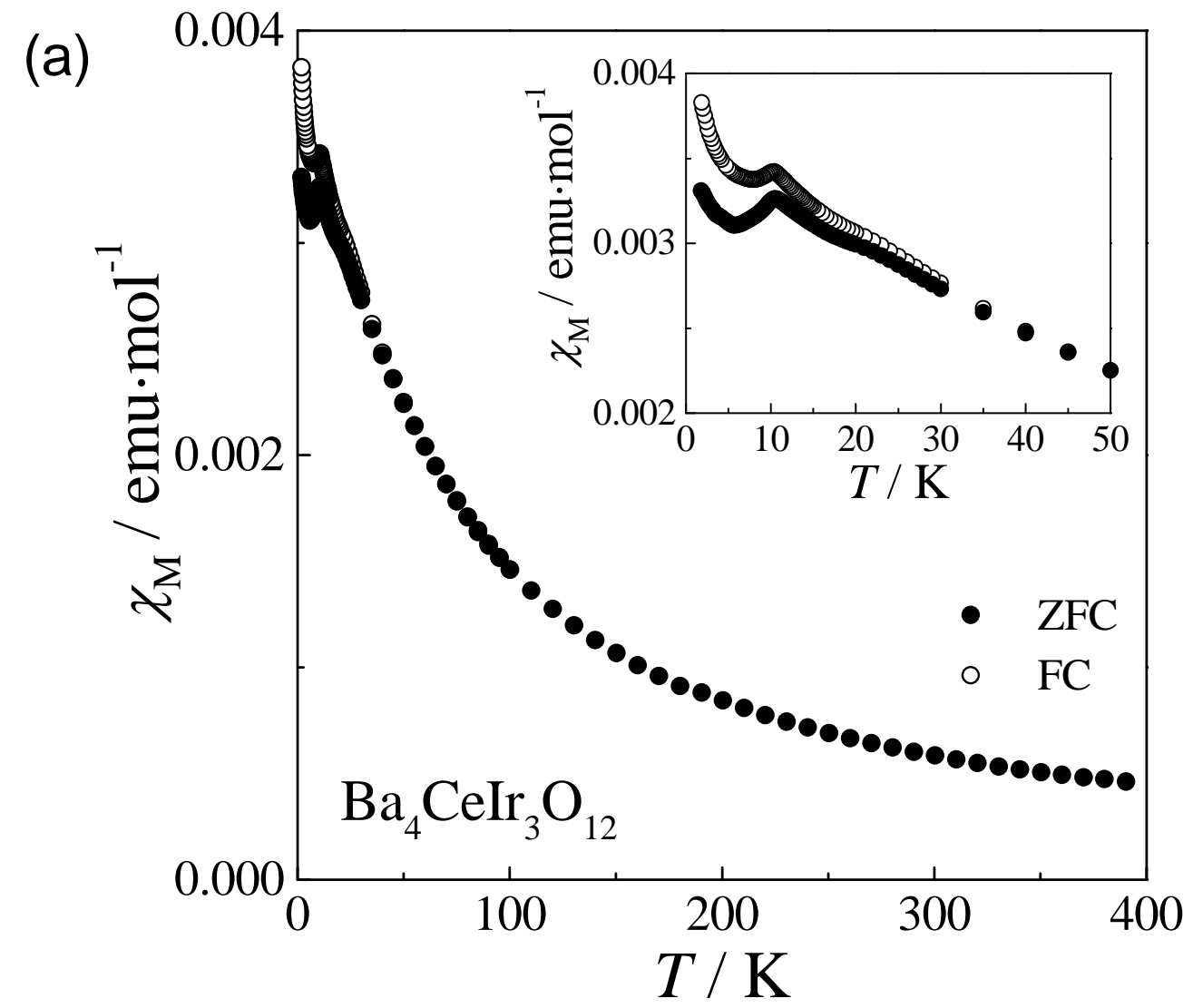

(b)

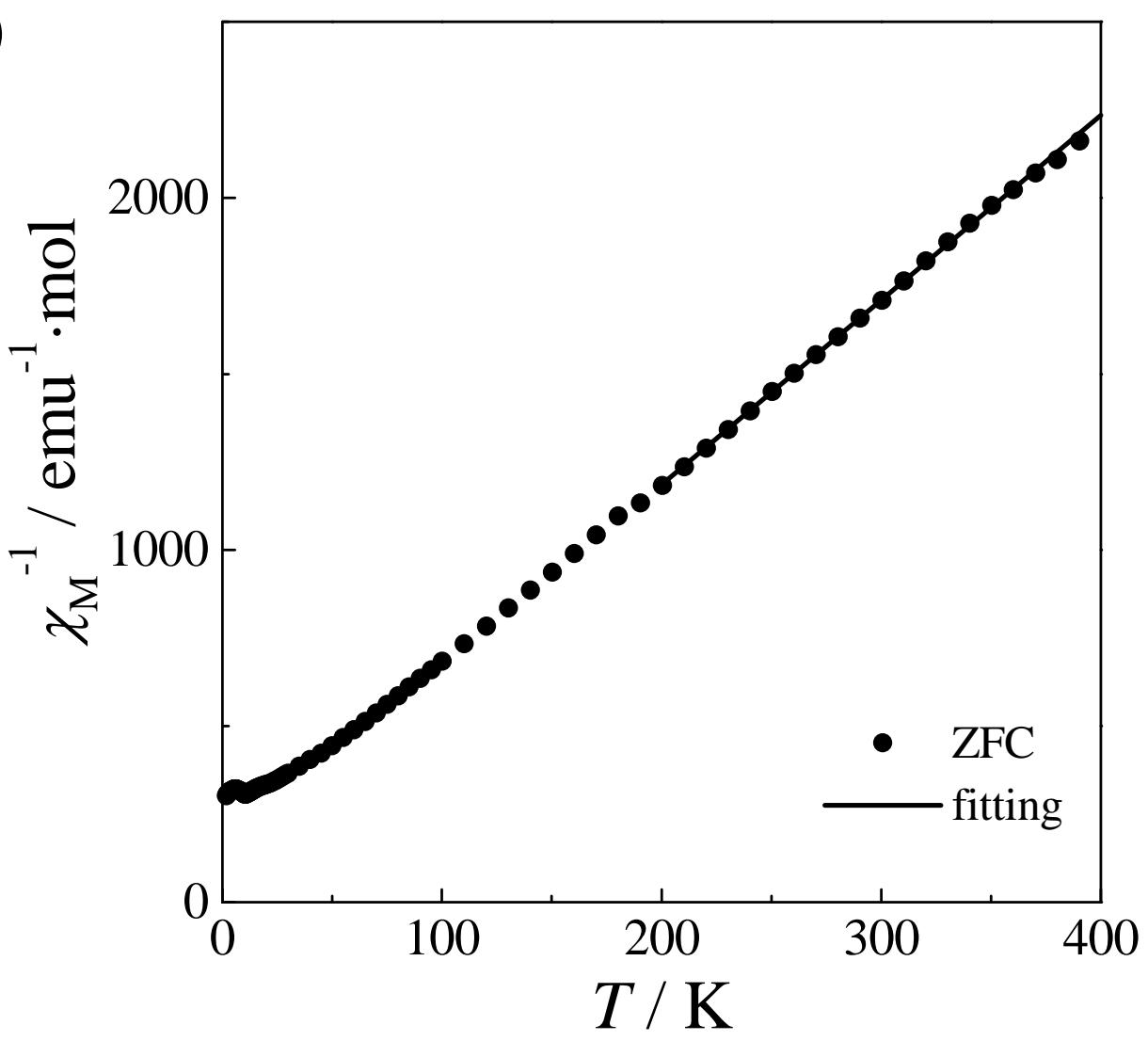

Fig.6 
(a)

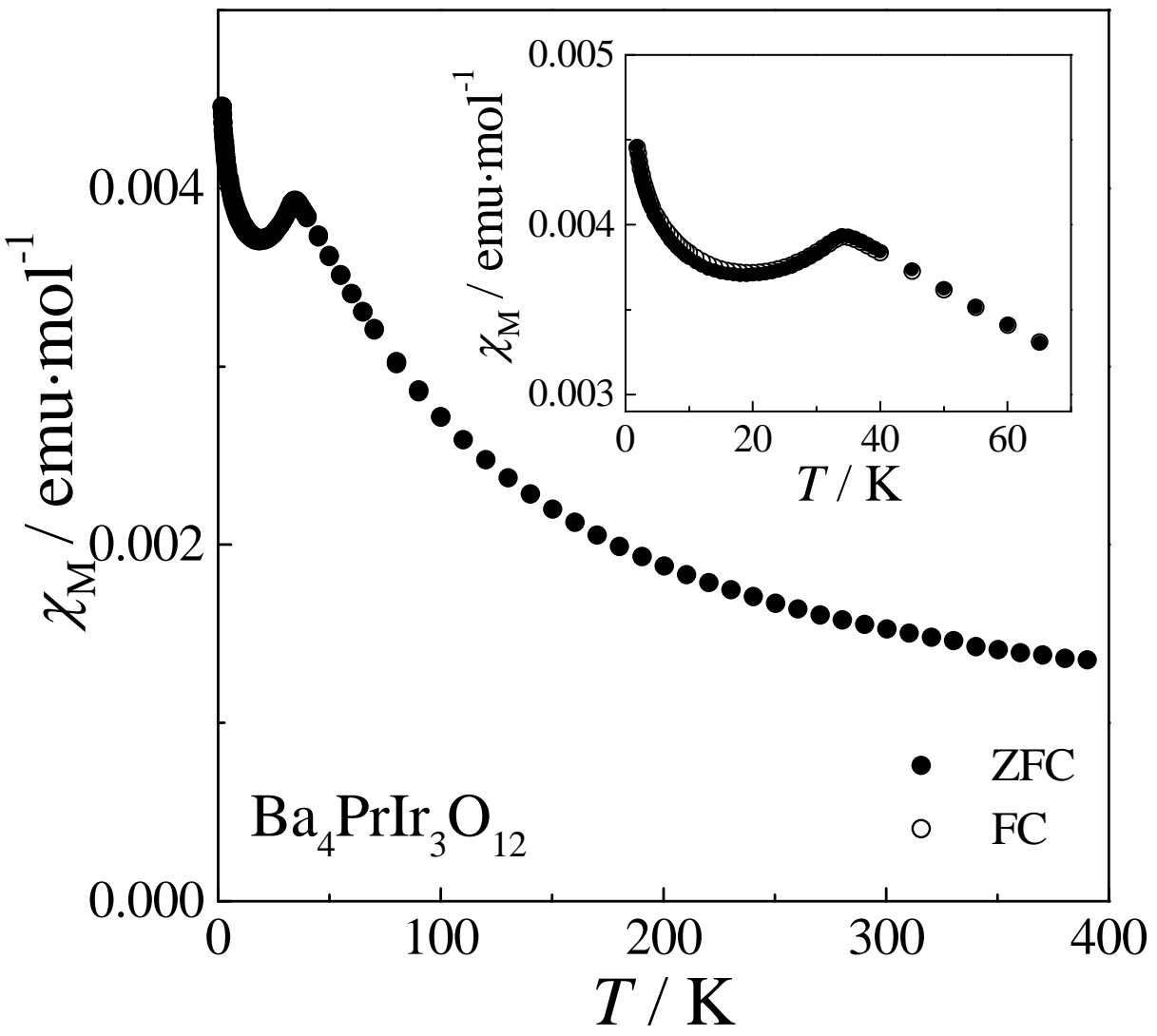

(b)

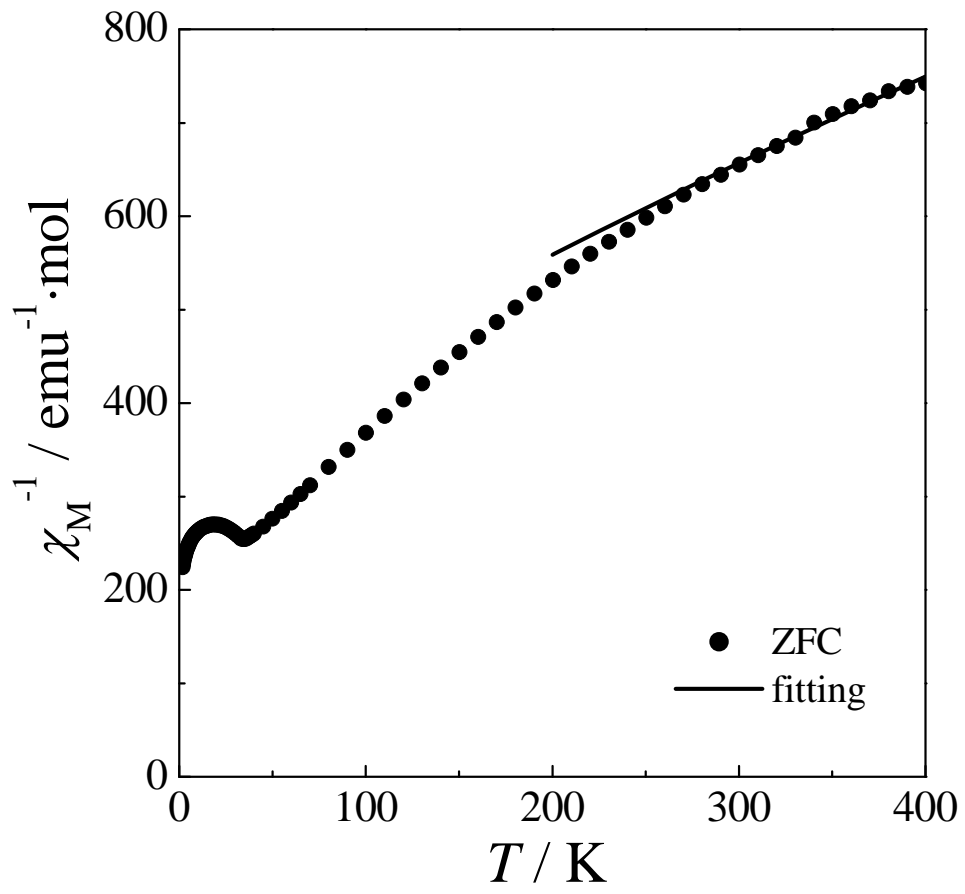

Fig.7 
(a)

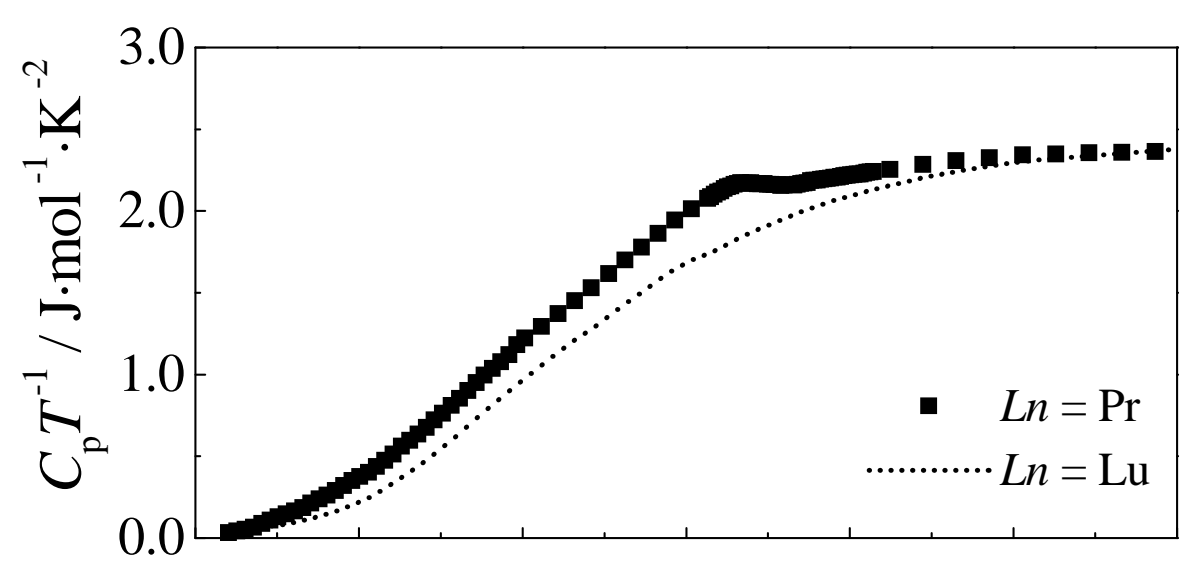

(b)

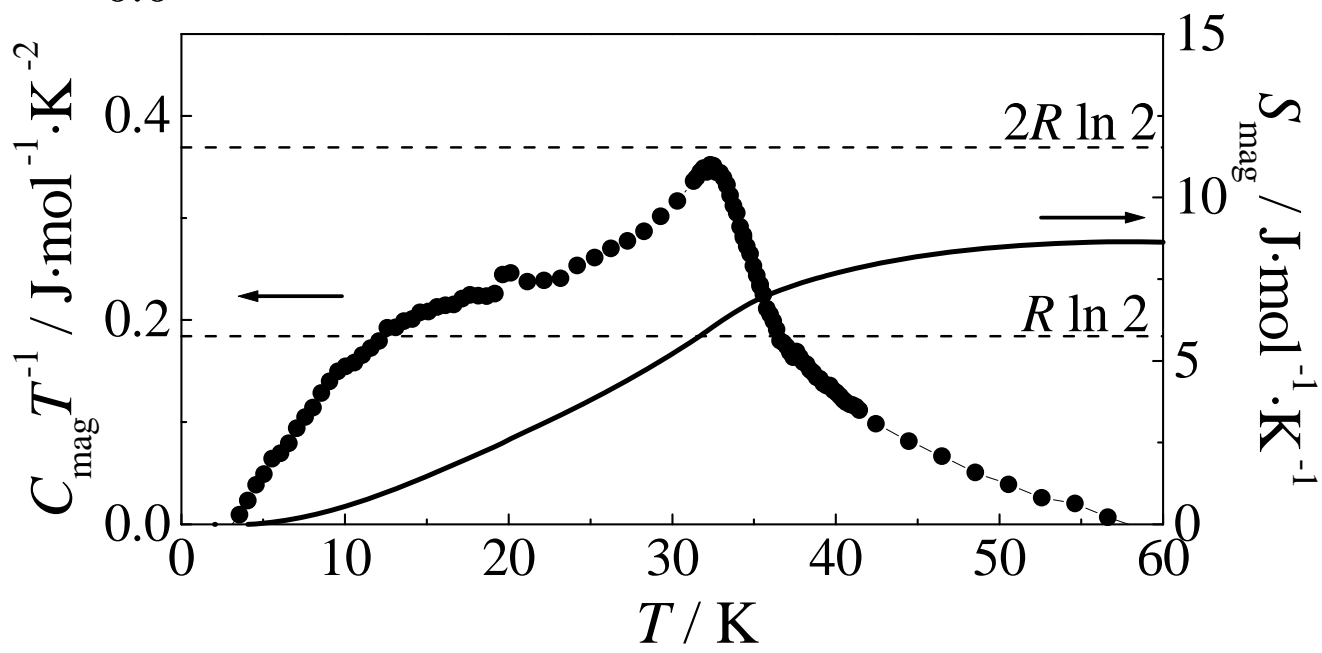

Fig. 8 
(a)

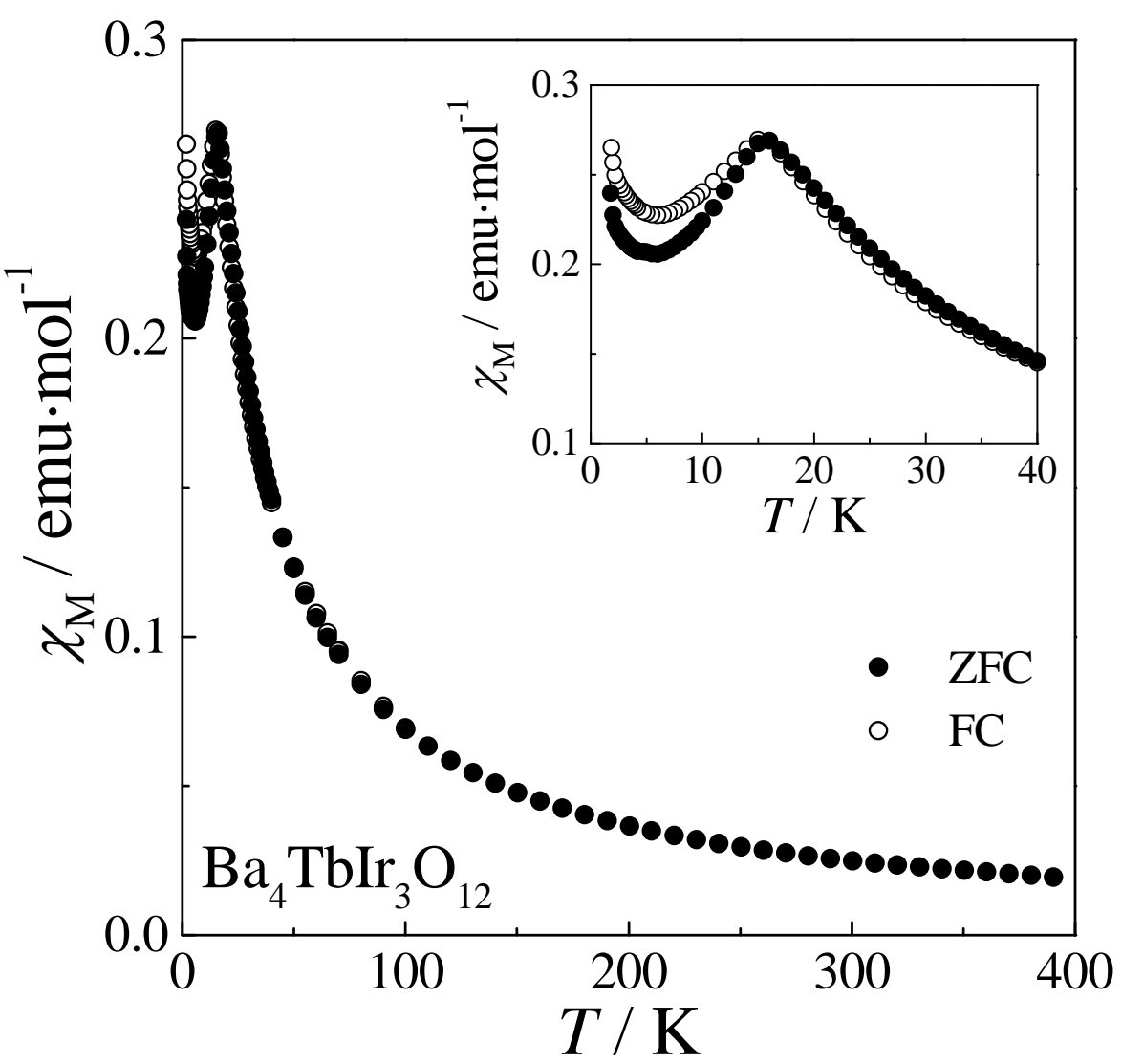

(b)

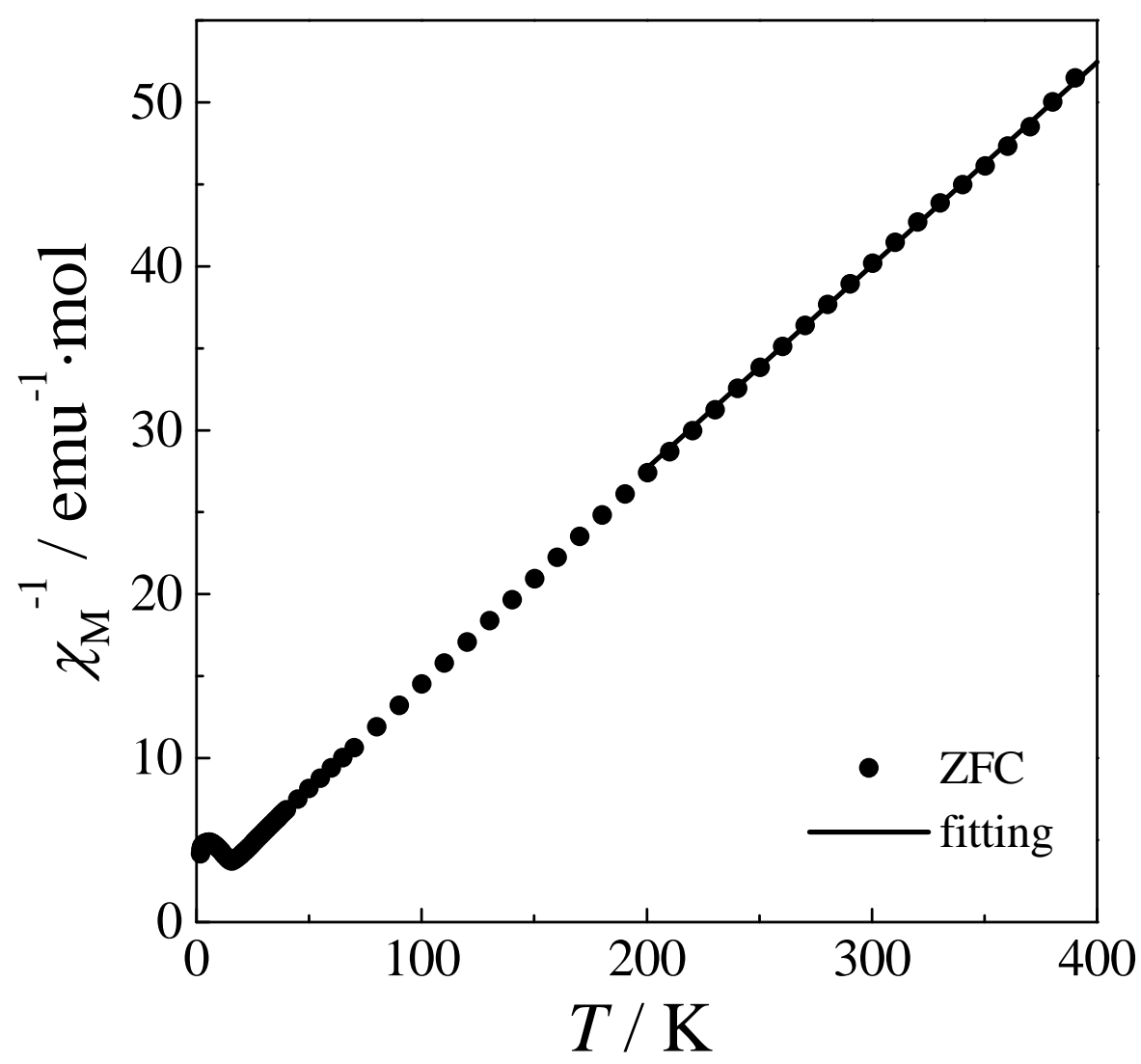

Fig.9 
(a)

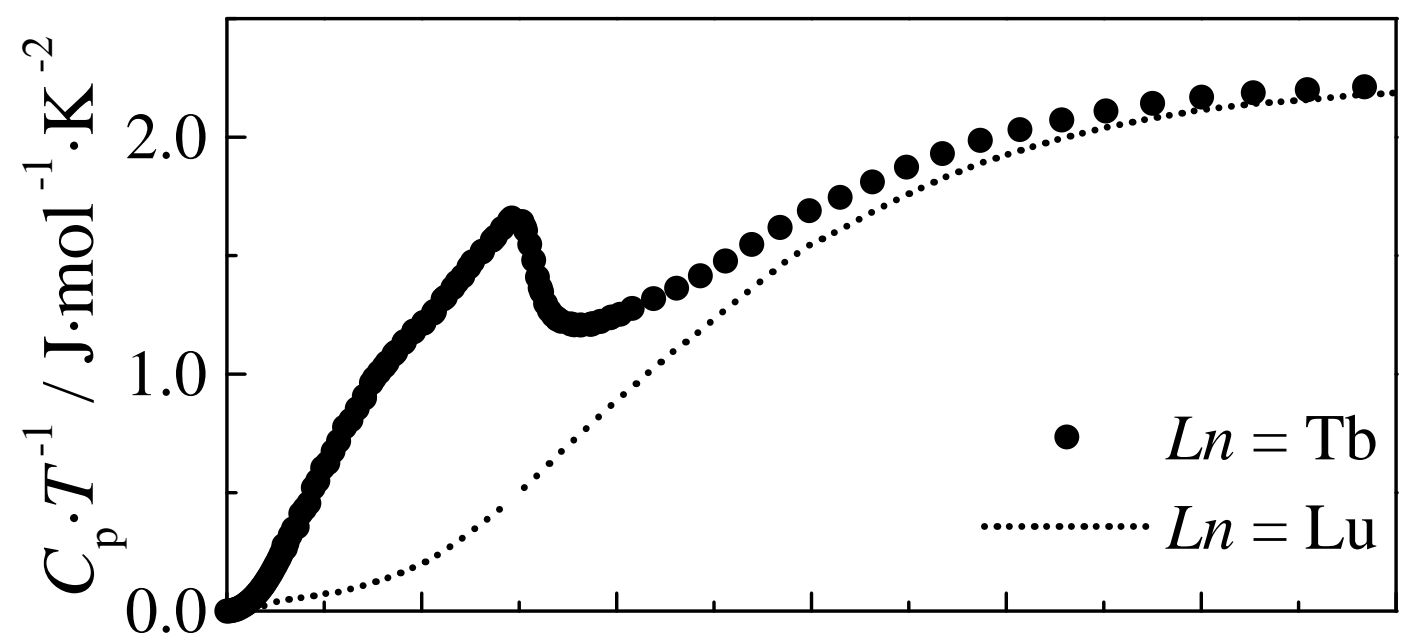

(b)

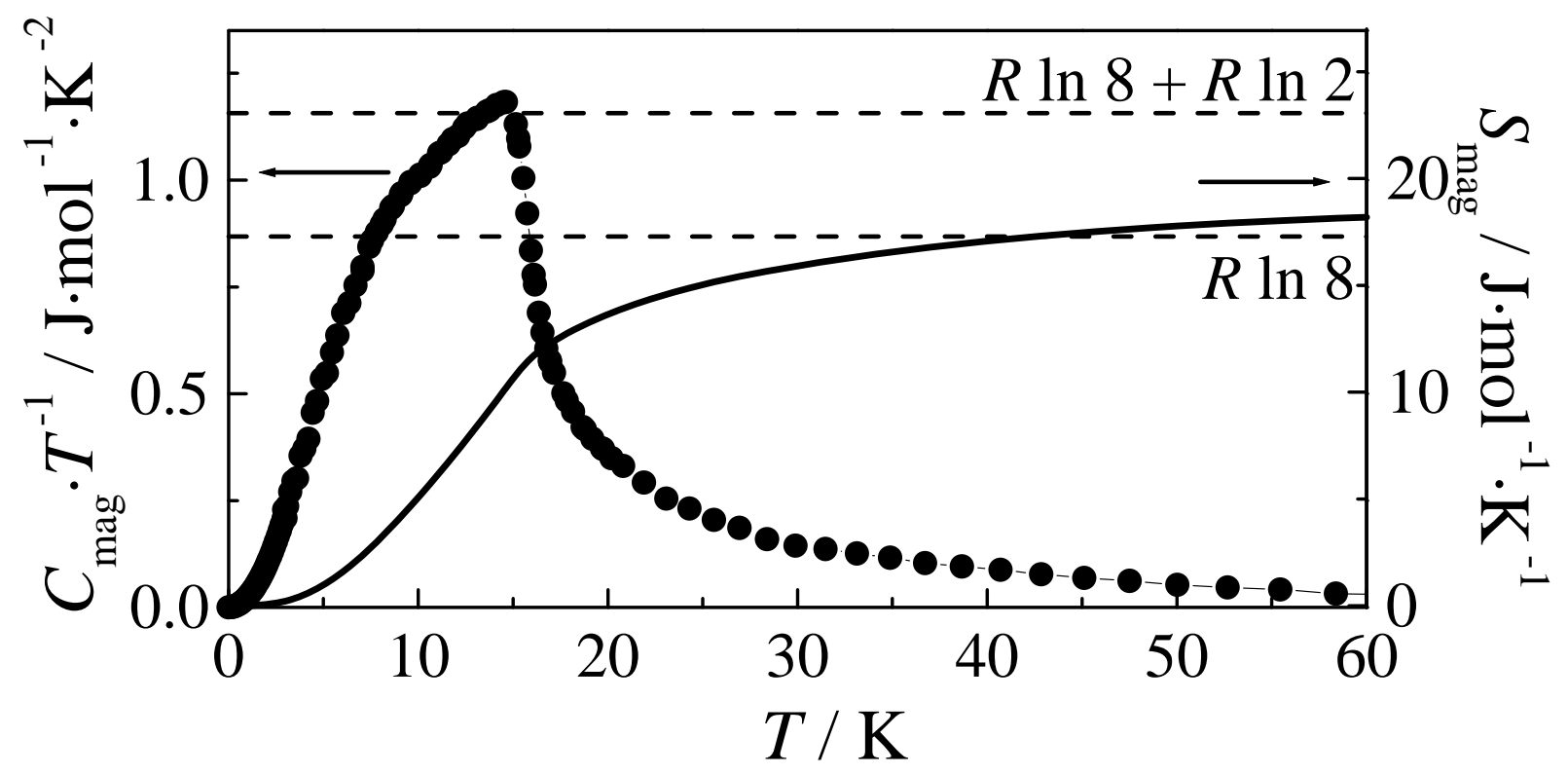

Fig.10 
Table 1. Magnetic properties for $\mathrm{Ba}_{4} L n \mathrm{Ir}_{3} \mathrm{O}_{12}$

\begin{tabular}{|c|c|c|c|c|c|}
\hline $\operatorname{Ln}^{3+}$ & $\begin{array}{c}\text { electronic } \\
\text { configuration }\end{array}$ & $J$ & $\mu_{\mathrm{eff}} / \mu_{\mathrm{B}}$ & $\mu_{L n}{ }^{\mathrm{a}} / \mu_{\mathrm{B}}$ & magnetic properties \\
\hline $\mathrm{La}^{3+}$ & $4 f^{0}$ & 0 & - & - & diamagnetic \\
\hline $\mathrm{Nd}^{3+}$ & $4 f^{3}$ & $9 / 2$ & 3.60 & 3.62 & Curie-Weiss \\
\hline $\mathrm{Sm}^{3+}$ & $4 f^{5}$ & $5 / 2$ & & 0.84 & van Vleck \\
\hline $\mathrm{Eu}^{3+}$ & $4 f^{6}$ & 0 & - & - & van Vleck \\
\hline $\mathrm{Gd}^{3+}$ & $4 f^{7}$ & $7 / 2$ & 7.98 & 7.94 & Curie-Weiss \\
\hline $\mathrm{Dy}^{3+}$ & $4 f^{9}$ & $15 / 2$ & 10.71 & 10.63 & Curie-Weiss \\
\hline $\mathrm{Ho}^{3+}$ & $4 f^{10}$ & 8 & 10.36 & 10.60 & Curie-Weiss \\
\hline $\mathrm{Er}^{3+}$ & $4 f^{11}$ & $15 / 2$ & 9.21 & 9.59 & Curie-Weiss \\
\hline $\operatorname{Tm}^{3+}$ & $4 f^{12}$ & 6 & 7.31 & 7.57 & Curie-Weiss \\
\hline $\mathrm{Yb}^{3+}$ & $4 f^{13}$ & $7 / 2$ & 3.86 & 4.54 & Curie-Weiss \\
\hline $\mathrm{Lu}^{3+}$ & $4 f^{14}$ & 0 & - & - & diamagnetic \\
\hline$L n^{4+}$ & $\begin{array}{c}\text { electronic } \\
\text { configuration }\end{array}$ & $J$ & $\mu_{\mathrm{eff}} / \mu_{\mathrm{B}}$ & $\mu_{\mathrm{cal}} \mathrm{b} / \mu_{\mathrm{B}}$ & $\begin{array}{c}\text { magnetic properties } \\
\left(T_{\mathrm{N}}\right)\end{array}$ \\
\hline $\mathrm{Ce}^{4+}$ & $4 f^{0}$ & 0 & 1.61 & 1.73 & antiferromagnetic $(10.5 \mathrm{~K})$ \\
\hline $\operatorname{Pr}^{4+}$ & $4 f^{1}$ & $5 / 2$ & 2.94 & 3.07 & antiferromagnetic (35 K) \\
\hline $\mathrm{Tb}^{4+}$ & $4 f^{7}$ & $7 / 2$ & 8.02 & 8.13 & antiferromagnetic (16 K) \\
\hline
\end{tabular}

a $\mu_{L n}$ : free ion values for $\mathrm{Ln}^{3+}$.

b $\mu_{\text {cal }}$ : calculated moments for $L n^{4+}$ and $S=1 / 2$ (see text). 